\title{
ECONOMICS AND MENTAL HEALTH
}

\author{
Richard G. Frank
}

Thomas G. McGuire

Working Paper 7052

http://www.nber.org/papers/w7052

\author{
NATIONAL BUREAU OF ECONOMIC RESEARCH \\ 1050 Massachusetts Avenue \\ Cambridge, MA 02138 \\ March 1999
}

Chapter for Handbook of Health Economics (Eds. Newhouse, Culyer). We are grateful for financial support from the Robert Wood Johnson Foundation (\#23498), the National Institute of Mental Health (MH3703 and K05-MH01263), and the Alfred P. Sloan Foundation. We thank Maggie Alegria, Randy Ellis, Jacob Glazer, Sherry Glied, Haiden Huskamp, Joe Newhouse, and Meredith Rosenthal for comments on earlier versions of this chapter. The views expressed in this paper are those of the authors and do not reflect those of the National Bureau of Economic Research.

(1) 1999 by Richard G. Frank and Thomas G. McGuire. All rights reserved. Short sections of text, not to exceed two paragraphs, may be quoted without explicit permission provided that full credit, including ${ }^{(}$ notice, is given to the source. 
Economics and Mental Health

Richard G. Frank and Thomas G. McGuire

NBER Working Paper No. 7052

March 1999

JEL No. I10

\section{ABSTRACT}

This paper is concerned with the economics of mental health. We argue that mental health economics is like health economics only more so: uncertainty and variation in treatments are greater; the assumption of patient self-interested behavior is more dubious; response to financial incentives such as insurance is exacerbated; the social consequences and external costs of illness are formidable. We elaborate on these statements and consider their implications throughout the chapter. "Special characteristics" of mental illness and persons with mental illness are identified and related to observations on institutions paying for and providing mental health services. We show that adverse selection and moral hazard appear to hit mental health markets with special force. We discuss the emergence of new institutions within managed care that address long-standing problems in the sector. Finally, we trace the shifting role of government in this sector of the health economy.

Richard G. Frank

Department of Health Care Policy Harvard Medical School 180 Longwood Ave.

Boston, MA 02115 and NBER

frank@hcp.med.harvard.edu
Thomas G. McGuire

Boston University

270 Bay State Rd.

Boston, MA 02215

tmcguire@bu.edu 


\section{Introduction}

In 1994, The Nobel Prize in Economics was awarded to the game theorist John Nash, who, in the early 1950s, formulated elegant mathematical models for the strategic interaction among small numbers of decision-makers in situations involving elements of both conflict and cooperation. The "Nash equilibrium" remains the most widely used equilibrium concept in game theory. Soon after his pioneering work was published, it was discovered that Nash suffered from schizophrenia. In the last thirty-five years, Nash has done little productive work, living in the care of hospitals, family, and friends. Many doubted that Sweden's Royal Society would award the Nobel Prize to a person with severe mental illness. When they did, Ariel Rubenstein, himself a prominent game theorist, expressed in a New York Times interview his admiration for Nash's work and his pleasure that the Royal Society acknowledged by their decision that there was nothing disqualifying about mental illness. Schizophrenia was, in Rubenstein's words, “just like cancer."

Public attitudes about mental illness have changed since the 1950s when Nash became ill, and the mentally ill have in many ways been integrated into the mainstream of the health care system. The fact remains, however, that in terms of public and private policy in the U.S., mental illness and substance abuse are not treated the same as other illnesses. In comparison to physical illness, governments pay for more of mental health and substance abuse (MH/SA) care, and private insurance pays for less. Treatment for mental and addictive disorders is often involuntary. This is rare for physical illness. The public mental health care system has had quality problems that are regarded as scandalous. The public system in mental health has a role as protector of public safety. When efforts have been made to reform the health care sector in the U.S., mental health and substance abuse care are usually handled separately. President Clinton's proposed 
health care reform in 1993, to take the most recent example, did not include long-term treatment for mental illness in the required services to be offered in health plans.

This chapter is concerned with the economics of mental illness and mental health care. Following convention, we will use the term "mental illness" to include substance abuse disorders such as drug or alcohol abuse and dependence. Mental health has been an active and distinct subfield of health economics for some time. Though mental health economics can claim no special methodology, it has its own conferences, training programs, and journals. ${ }^{1}$ Mental health economics is like health economics only more so: uncertainty and variation in treatments are greater; the assumption of patient self-interested behavior is more dubious; response to financial incentives such as insurance is exacerbated; the social consequences and external costs of illness are more formidable. We will elaborate on these statements and consider their implications throughout this chapter. "Special characteristics" of mental illness, and the persons with mental illness, will be identified and related to the observance of institutions paying for and providing mental health care. When Pauly (1988) asked, "Is Health Care Different?", he was contrasting health care with the rest of the economy. Here we explore the question: "Is mental health care different from health care?"

The first reaction for many people is to answer "yes" to this question, and give the reason as stigma. Literally, a "mark" or a "stain," stigma sets persons with mental illness apart as undesirable. Nunnally (1961) found that regardless of the respondent's education, the mentally ill were regarded as dangerous, unpredictable, and socially of little value. In one of the few studies comparing attitudes over time, Matas et al. (1986) analyzed treatment of mental illness in the

\footnotetext{
${ }^{1}$ Much of this is due to support from the National Institute of Mental Health in various forms. The late Carl Taube was the official of the NIMH who was most responsible for promoting the field of economics of mental health.
} 
press, concluding that in spite of some "minor, cosmetic changes," overall, "content and attitudes had changed little."2 One hopes that national educational campaigns such as the NIMH's Depression Awareness initiative have had some effect, but the degree is hard to judge. It seems safe to say that some part of the public's fear of the mentally ill remains irrational and misplaced. ${ }^{3}$ The historical importance of stigma calls attention to the salient point, important to the rational as well as the irrational side of the story, that differential treatment of mental health care for purposes of policy will be driven not just by differences in the disease and its treatment (e.g., demand is more responsive), but differences in the people who have the disease (e.g., they are more costly in other ways). This chapter, using methods of economics, will be concerned with the more "rational" reasons why mental illness is treated differently than other illnesses, without claiming that this is the full picture.

The core issues in mental health and health economics include:

- Adverse Selection and Moral Hazard: These are traditional concerns in health economics. We will argue that these features of insurance markets apply with particular force for mental health care.

- Non-contractable provider actions. The term "noncontractable" was not in use when Arrow wrote his overview of health economics, but he clearly had this in mind when he discussed the ways health markets adapt to ensure that physicians put sufficient effort into caring for patients. Maintaining effort in a managed care environment is a problem for all areas of care. We will argue that it may be especially problematic in mental health due to the severity of selection-related incentives. At the same time it appears that special institutions are arising (a la Arrow) that may be capable of contending with some of these unwanted consequences.

- Externalities: Mental disorders are often chronic conditions that create substantial disability and strike people early in life (ages 15 to 30). These illnesses are correlated with

\footnotetext{
${ }^{2}$ Prejudice against the mentally ill on the part of the nominating committee for fellowship in the prestigious Econometric Society thwarted Nash's induction in 1988, according to Nasar (1998). Two years later the nominating committee was bypassed and Nash was elected directly by the members in an overwhelming vote.

${ }^{3}$ Link and Cullen (1986) demonstrate that the more people have direct contact with persons with mental illness, the less dangerous they are regarded, supporting this conclusion.
} 
other costly social problems: unemployment, crime, violence, and homelessness. Many of these problems have consequences for others as well as the person with the illness. For this reason government has historically taken a large role in provision and regulation of some forms of mental health care.

The mental health sector contains institutions, professions, and illnesses that are unfamiliar to policy analysts and even to specialists in health economics. As such, policy has often been applied to the institutions of the mental health sector as an afterthought to a broad health policy decision. We hope to introduce some of the special institutional features in MH/SA to a health economics audience and to review some of the empirical research that has been focused on mental health issues. In addition, we will review some of the policy trade-offs facing those interested in remedying market failures in the mental health sub-sector.

This chapter is organized into six main sections. Following this introduction is a description of the institutional context within which mental health and substance abuse care is provided. This includes a discussion of mental and addictive illnesses, their consequences, and the organizations involved in financing and delivery of care. The third section focuses on issues of moral hazard and rationing of care. Evidence on the impact of benefit design and payment policies is assessed. A general framework for analyzing rationing of treatment within managed care is presented, which allows us to evaluate the case for "parity" for mental health in health care payment systems within a managed care environment. Adverse selection is addressed in the fourth section. The rationing model developed in the previous section is applied to selectionrelated behavior by managed health care plans. The reasons why mental health might be more vulnerable to selection-driven market features are set out. Risk adjustment and behavioral health carve-outs are examined as institutions aimed at countering selection-related incentives. The fifth 
section focuses on externalities and the role of state government in the delivery of mental health and substance abuse care. We offer some concluding observations in the sixth and final section.

\section{The Institutional Context}

The nature of mental illness, the persons with mental illness, use of treatment services, and the supply side of the market differ from the general health sector.

\section{A. Mental Illness and Persons with Mental Illness}

World-wide, mental illness is among the most prevalent and disabling illnesses. In the U.S., approximately $29.5 \%$ of the population is estimated to experience some diagnosable mental or addictive disorder in a 12-month period (Kessler et al., 1993). Some diseases have been found to be roughly similar in high and middle income countries when the same epidemiologic assessments are applied (Weissman et al., 1995). However, comparative epidemiological studies show considerable variation in illness patterns across nations. For example, rates of depression are estimated to be considerably lower in Puerto Rico than in the U.S. or Switzerland. Substance abuse is much higher (roughly 4 times higher) in the U.S. and Puerto Rico than in Switzerland (Swendsen et al., 1997).

The most severe mental disorders, schizophrenia, manic depression, and some forms of major depression affect about $4 \%$ of the population each year and are very disabling. Within this group are the psychoses, illnesses associated with severe disturbances in cognitive functions. These disorders are persistent illnesses that tend to have initial onsets relatively early in life (ages 15 to 30). Individuals with these serious illnesses most often suffer for relatively long periods (APA, 1995). Severe forms of mental illness reduce an individual's ability to function in the consumer role, and interfere with the maintenance and creation of social networks (family and 
friends) weakening the connection with others who might serve as caregivers or proxy decisionmakers (Segal, Silverman, and Baumohl, 1989).

Effective treatments, primarily drug therapy, reduce symptoms and improve functioning for all of these illnesses. Existing treatments contend with but do not "cure" mental illness, and persons with these illnesses require long-term monitoring and treatment as well as periods of intensive services such as hospitalization. Many require extended periods of assistance with housing and social support, contributing to the need for a public risk in caring for this most severely ill group.

Mental and addictive disorders are costly to society both in terms of direct spending on treatment as well as in terms of the losses sustained as a consequence of the disorders. Spending on mental health and substance abuse care (MH/SA) in 1995 was estimated to be about $\$ 75$ billion (Triplett, 1998), amounting to about $8.3 \%$ of personal health expenditures. Overall spending on MH/SA in the U.S. (including specialty and general care) grew at $13 \%$ per annum during the 1963-1972 period, at $14 \%$ per year during 1972-1980, and $9.3 \%$ in the $1980-1995$ time span. Total health care spending grew at yearly rates of $11.5 \%, 13.7 \%$, and $9.9 \%$ for the three time intervals respectively. This suggests that mental health spending tracked overall spending quite closely over the 1963-1995 period (Triplett, 1998).

While the United States spends more on MH/SA in absolute terms than do other western nations, it spends a lower proportion of personal health outlays than Great Britain (16.6\%), Canada (11.4\%), and Australia (8.4\%) (Triplett, 1998). Mental disorders impose costs on the individual, his or her family, and on society as a whole. In aggregate, Rice et al. (1990) found indirect costs to be twice the direct costs of care. Studies of individual behavior have documented the impact of mental health on employment, productivity and earnings (Berndt et al., 1997; Ettner 
et al., 1997; Bartel and Taubman, 1986; Mullahy and Sindelar, 1993), criminal activity (Steadman et al., 1998; Link, 1992), motor vehicle accidents (Rice et al., 1990), child abuse and neglect (Kelleher et al., 1994), homelessness (Jencks, 1994), and divorce (Bartel and Taubman, 1986).

The indirect cost of mental illness has also been studied in terms of employment and earnings. A common finding in psychiatric epidemiology is an inverse correlation between income and rates of illness in a population (Bruce, Takeuchi, and Leaf, 1991). However, the causal connection between mental illness and income and other labor market outcomes is complex. Economic stress, such as involuntary unemployment, may aggravate illness. Some difficult-tomeasure personal characteristics which make a positive contribution to earnings are correlated with some illnesses. Creativity, energy, and attention to detail may each be more common among persons who have mania or obsessive-compulsive disorders. Furthermore, persons who have diseases and are successful enough to remain in the labor force may have atypical values of some other unmeasured labor market characteristics. Estimates of the impact of mental disorders on labor market outcomes have used longitudinal data, or instrumental variables and cross-sectional data to find substantial reductions in earnings and other measures of productivity associated with illness. Bartel and Taubman (1986), and Frank and Gertler (1991) use longitudinal data with information on prior illness to estimate reductions in earnings of men of between $20 \%$ and $25 \%$ for conditions that are thought to produce the most impairment such as psychotic disorders and major depression. Neuroses and other mental disorders had smaller but significant negative impacts on earnings (5\% to 15\%). Ettner, Frank and Kessler (1997) used cross sectional data from a national epidemiological survey of the U.S. population to examine the effect of mental and addictive illnesses on employment and earnings. Information on the family history of mental illness and the timing of the onset of symptoms of mental illness enabled the authors to use 
instrumental variable techniques to estimate the impact of mental illness on income taking account of possible endogeneity of mental illness. They found that the presence of a diagnosable mental illness reduced employment by about $11 \%$ for both males and females and for those who worked, the estimated loss of income attributable to mental illnesses was about $20 \%$ for women and $10 \%$ for men.

The connection between mental disorders and violence and crime has been controversial, since it is tied so closely to the sensitive issue of social stigma. Recent research has found clear evidence that mental illness and substance abuse are associated with higher rates of criminal activity. A study by Link and colleagues (1992) illustrates the tenor of a larger set of research findings. When psychiatric patients are compared to a control population, matched according to the neighborhood in which they live and socioeconomic characteristics, psychiatric patients exhibit significantly higher rates of weapon use and violent behavior. Torrey (1994), an advocate for the seriously mentally ill, arrived at a similar conclusion based on a review of the literature, stating: "Although the vast majority of individuals with serious mental illness are not more dangerous than members of the general population, recent findings suggest the existence of a sub-group that is more dangerous" (p.653). According to Steadman et al. (1998), the subgroup includes those individuals with a co-occurring substance abuse disorder. Individuals who suffer from both mental illness and substance abuse problems are more likely to be involved in violence than otherwise similar people with mental illness only or without mental illness. (It is notable that individuals with a mental disorder are significantly more likely to abuse substances than are people without such illnesses.)

Addictive disorders have also been tied to auto accidents (see Rice et al., 1990 for a review), unsafe sexual practices and child abuse and neglect (Kelleher et al., 1994). Alcohol and 
drug abuse in mothers has also been linked to poor birth outcomes (Secretary of DHHS, 1993; ASPE, 1994). Even at levels of use that do not qualify as "abuse", alcohol and drug use can be problematic, especially among the young. Lowry et al. (1994) report that high school students were more likely to engage in risky sexual behavior if they used alcohol (relative odds of 2.7), marijuana (odds of 9.2) or cocaine (odds of 26.8) relative to non-users.

Finally, homelessness has often been linked to mental illness and substance abuse in both recent literature (Jencks, 1994) and the popular press. Many mental hospital patients were shifted to nursing homes, jails, and streets as a result of the reduction in public mental hospital capacity during the 1960s and 1970s (O'Flaherty, 1996). Jencks contends that the "deinstitutionalization" movement was a prime cause of the growth of homelessness during the 1980's, while other observers (e.g. O'Flaherty, 1996) have questioned the strength of the causal connection.

This brief profile of mental and addictive disorders and their social consequences leads to two conclusions useful for an economic analysis of mental health and mental health care. First, mental and addictive disorders are prevalent and associated with a variety of social costs not incurred by the affected individuals. The existence of externalities means that decentralized market decision-making will tend to undervalue effective treatments for mental and addictive illnesses. Second, the social costs of mental and addictive disorders are concentrated in the $4 \%$ of the population that experience the more severe forms of the disorders. This sub-group of people displays a series of characteristics that make them "undesirable" to insurers as clients, employers as workers and to significant segments of the general population as neighbors. Thus, in the absence of some compensatory factor, there are selection-related private benefits linked to avoiding employing and insuring those at risk for mental illness.

\section{B. Who is Treated for Mental Illness}


One of the dilemmas in formulating policy towards mental health care is that "undertreatment" and "overtreatment" can coexist within the same payment system. Of the $30 \%$ of the population that has a mental illness at some point during a year, only $17.3 \%$ get some treatment in the health care sector with an additional $7.4 \%$ getting their only treatment from a human service agency or a self-help group (e.g. Alcoholics Anonymous). ${ }^{4}$ Thus, only about $25 \%$ of those with a diagnosable condition get some form of treatment over a twelve-month period. Low rates of treatment conditional on having a disorder also characterize the more severely ill. Only $36 \%$ of those with manic depression or major depression in a year are treated in any sector, and only $25 \%$ of those with substance abuse are treated. (Approximately $57 \%$ of individuals with schizophrenia do get some health care treatment.)

At the same time, $4.5 \%$ of individuals with no disorder (assessed with a diagnostic instrument) receive mental health care from a health care provider and $8.2 \%$ get treatment from some human service organization or self-help group. Those individuals with no diagnosed condition that obtain treatment make almost the same number of visits as those with at least one diagnosed condition: 7.9 visits per year compared to 9.3 visits (Kessler et al., 1997). Putting this together with the figures in the earlier paragraph, we can say that nearly $38 \%$ of all users and $28 \%$ of all visits for mental health care are not associated with a diagnosable disorder. ${ }^{5}$ Moreover, a large segment of that group report that they are in either good or excellent emotional health (see

\footnotetext{
${ }^{4}$ All the data cited in this paragraph are based on information from the National Comorbidity Survey. Detailed discussion of these findings is in from Kessler et al. (1997).

${ }^{5}$ The share of the total population that are both users of care and have a diagnosable condition is $0.05(0.17 \mathrm{x}$ 0.30). The share of the total population that use services but do not have a diagnosable condition is $0.03(0.045$ $\mathrm{x}$ 0.70). Thus $38 \%$ of the users do not have a diagnosable condition.
} 
Kessler et al., 1997). ${ }^{6}$ It is interesting to note that in Canada the portion of users of MH/SA care who have no disorders is considerably smaller than in the U.S. (Kessler et al., 1997).

Spending on treatment is concentrated on those people with the most disabling conditions. It was estimated that in 1990 nearly $30 \%$ of spending on mental health and substance abuse care was accounted for by $5 \%$ of the users of care (Frank et al., 1994). For example, the mean level of spending on treatment of mental health and substance abuse care in a large insured population for 1993 was $\$ 8$ per enrollee per month, while the mean cost of treating someone with a diagnosis of manic depression was about $\$ 6,700$.

People with a history of mental health care use also tend to incur higher levels of general health expenditures than do others. For example, data from Michigan Medicaid indicate that the average person had expenditures of $\$ 1,873$ per year in health care over a three-year period (19911993) compared to $\$ 3,722$ (including mental health care) for individuals with any treatment for mental illness during that time period. Roughly $66 \%$ of the difference is accounted for by mental health costs. Cuffel and Goldman (1998) report that mental health care users spend nearly 90\% more on general medical care than did non-users.

A large segment of individuals who receive the highest intensity of care do so, in part, because they are compelled to by the legal system. For example, in 1994, approximately $43 \%$ of days of care provided in specialty psychiatric hospitals and specialty psychiatric units of general hospitals were accounted for by individuals involuntarily admitted. In addition, $27 \%$ of days of

\footnotetext{
${ }^{6}$ Results from an epidemiological survey in Ontario suggest that people with the most disabling illnesses are somewhat more likely to get treatment in Ontario (Kessler et al., 1997b). The U.S. may perform relatively badly on this score.
} 
care in residential facilities and $8 \%$ of patients in ambulatory settings were involuntarily placed in care. $^{7}$

\section{Who Pays for Mental Health Care}

Spending on mental health and substance abuse care displays a different pattern than that found in the health sector overall. Table 1 reports the composition of spending on health and MH/SA care in the U.S. Among the most important differences reported in the Table is the role of government as a direct funder of care. The other federal (block grants) and other state and local categories comprise $23.3 \%$ of all $\mathrm{MH} / \mathrm{SA}$ spending compared to $11.5 \%$ of overall healthcare spending. In addition, Medicaid plays a somewhat larger role in $\mathrm{MH} / \mathrm{SA}$ spending, $18.8 \%$ vs. 14.8\%. Finally Medicare plays a considerably smaller part in funding MH/SA than it does for all health services. Thus state and local government generally allocated more resources for MH/SA, 42.1\% (summing block grant, state/local and Medicaid) than for health services generally, $26.3 \%$. This highlights the differing division of labor between federal and state government. Whereas the federal government funds over $25 \%$ of health spending, it accounts for less than $20 \%$ of $\mathrm{MH} / \mathrm{SA}$ expenditures.

Table 1 shows that private health insurance accounts for a smaller share of spending in MH/SA than in all health care $(25.8 \%$ vs. $31 \%)$. The table also suggests that private out-ofpocket spending makes up a smaller share of non-public funding in MH/SA than in overall health care. As we shall see below, this finding is inconsistent with data on insurance coverage and may be an artifact of using insurance claims to estimate private spending.

\section{The Supply of Mental Health Services}

\footnotetext{
${ }^{7}$ These data are based on unpublished information from the Inventory of Mental Health Organizations collected by the Substance Abuse and Mental Health Services Administration of the USDHHS, 1996.
} 
There are a great variety of organizations and professionals that supply mental health services, not limited to traditional medical care providers. For example, in the state of Massachusetts one could receive office-based psychotherapy from any of the following licensed providers: primary care physicians, psychiatrists, psychologists, social workers, counselors, and nurses. The services provided by each of these professions are paid for by public and private insurance plans. Similarly, inpatient psychiatric care might be provided in the medical-surgical section of a general hospital, a general hospital psychiatric unit, a private psychiatric hospital or a state mental hospital. In some cases the functions of these various suppliers are differentiated and in others they offer services that appear to be close substitutes (Goldman and Skinner, 1989).

Table 2 describes the types of organizations that offer specialty mental health services in the U.S. and their nominal levels of spending in 1969 and 1994. Note the dramatic shifts in patterns of spending within the hospital sector and between hospital and non-hospital organizations over time. For example, state mental hospitals accounted for about 55\% of all specialty mental health spending in 1969 compared to roughly $25 \%$ in 1994 . General hospitals accounted for $9 \%$ of spending in 1969 compared to $16 \%$ in 1994 . Community based treatment programs (which include mental health centers) accounted for 7\% of spending in 1969 and $11 \%$ in 1994. These changes in the roles of suppliers of mental health care also reflect the emergence of markets that has taken place over the past 40 years. Even public funds are increasingly allocated via markets. Insurance mechanisms like Medicaid have grown in importance over time. Public managed care programs turn over operations of systems of care to private organizations. Whereas publicly owned and operated mental hospitals dominated the supply of care in the 1950s and 1960s, privately owned non-profit hospitals, mental health centers and clinics now play a central role, as do private for-profit organizations. These new treatment sites emphasize 
outpatient therapy, management of drug treatments, partial hospital services, rehabilitation and case management services.

Psychiatrists and psychologists account for less than half of mental health professionals. While there were about 33,500 psychiatrists and nearly 70,000 psychologists in 1995 , social workers, counselors, and family therapists accounted for 94,000, 61,000 and 46,000 practitioners respectively. Individuals with higher income and private insurance receive mental health care from physicians, psychologists, or social workers specializing in mental health services. Shifting patterns of supply correspond to altered approaches to treating mental illnesses.

The treatment of mental illnesses has changed dramatically over the past 40 years, in part due to scientific changes in treatment technology such as pharmaceutical innovation (Berndt, Cockburn and Griliches, 1997; Grob, 1991), new methods of organizing elements of treatment (Stein and Test, 1980), and improved approaches to brief psychotherapy. Changes in the organization and financing of mental health services have also contributed to changing treatment patterns (Mechanic, 1989). In particular, limits on insurance coverage for inpatient days or outpatient visits, financial incentives to reduce hospital stays and payment arrangements which reward health plans for reducing overall health care spending have contributed to shifts in treatment of mental and addictive disorders (Harrow and Ellis, 1992; Frank and McGuire, 1996). Various types of mental health services have been posited to be substitutes. Research based in HMOs and publicly funded treatment programs provides evidence indicating that community based outpatient treatments are substitutes in production for inpatient hospital care (see Weisbrod, 1983; Stein and Test, 1980; Hoult et al., 1981; Finch et al., 1992; Callahan et al., 1995). Similarly for psychotherapy services, outcomes evaluations suggest that there are a range of professions trained in psychotherapy that produce comparable clinical gains to patients, 
implying that these professions are substitutes in production of psychotherapy treatment (Knesper, 1989).

There is also mounting evidence that for certain specific illnesses pharmaceutical treatments can substitute for psychotherapy (Elkin et al., 1986; Kupfer et al., 1993). Berndt, Frank and McGuire (1997) offer evidence that drugs and psychotherapy are also substitutes in demand. Empirical analyses of cross-price responses of demand for social workers' and psychologists' services relative to psychiatrists' indicates that a substantial segment of the services delivered by each profession are also close substitutes in demand (Fairbank, 1989; Frank, 1985).

Data on medical practice patterns indicate that there is considerable disagreement about how medical treatments of all types, health and mental health care, should be used. Holding other factors constant, the likelihood of receiving a particular treatment can vary dramatically based on a patient's residence (Phelps, 1998). Phelps and Mooney (1993) contend that much of the variation in practice is due to beliefs, information, and learning at the individual physician level. If variation is unrelated to differences in patient need or benefit, it will cause significant welfare loss. In the mental health area, variation in treatment tends to be greater than in medical care overall (Phelps, Handbook). This may, in part, be explained by the wide range of professions (with their theoretical orientations) and modalities (with their patterns of costs and incentives) that supply treatment to individuals with a particular illness. It may also reflect greater clinical uncertainty. With more disagreement among clinicians about proper treatment, welfare losses from treatment not related to benefits may as a result be larger in the mental health area. ${ }^{8}$

\section{E. Managed Behavioral Health Care}

\footnotetext{
${ }^{8}$ The variation and welfare loss must take into account other factors. Even granting that variation is around an "optimal point," the welfare loss depends on the shape of the total benefit schedule. A flat marginal benefit function, associated with an elastic demand will imply a relatively low welfare loss.
} 
Managed care is transforming the health care sector generally, and may be having more of an impact on mental health than in health care. Employers, government and other purchasers are bargaining for lower prices and monitoring treatment patterns. The response to the new spirit of prudent purchasing of health care services has been an acceleration in the growth of managed care organizations. Preferred Provider Organizations (PPOs), Point of Service (POS) plans and Health Maintenance Organizations (HMOs) accounted for 73\% of the insured population in 1995 (PPRC, 1997). State governments have moved to strengthen the bargaining power of buyers of health care by encouraging the creation of purchasing alliances that enable smaller purchasers of group health insurance to command more choice at more advantageous prices. State Medicaid plans and the federal Medicare program are all experiencing rapid growth in enrollment of beneficiaries in managed care organizations that bear significant financial risk.

A striking development in mental health and substance abuse has been the development of so-called managed behavioral health care carve-outs. Traditionally, the purchaser, usually an employer, contracted with a single insurance plan to cover a full range of health risks. Increasingly, however, purchasers of health insurance are offering beneficiaries a range of plans. Purchasers may also "carve out" certain benefits, which means that they separate the health insurance function by disease or service category and contract separately for the management of those risks. This carve-out in insurance need not be associated with "managed care," but it virtually always is.

There are three forms of carve-outs found in the MHSA health sub-sector, with potentially distinct economic impacts. They are: a) payer specialty carve-outs from all health plans; b) payer 
specialty carve-outs from only indemnity and PPO type arrangements; and c) individual health plan carve-outs to specialty vendors.

The two forms of payer carve-outs are illustrated in Figures 1 and 2. In Figure 1, enrollees have a choice among a traditional indemnity insurance plan and managed care plans (e.g. an HMO and a PPO). The payer in this case writes a separate contract with a specialty vendor, for the carved out service (e.g. behavioral health), to manage a segment of the risk in the traditional plan. Some well-known carve-out programs are of this type, the Massachusetts Medicaid (Callahan, et al., 1995; Frank and McGuire, 1997; and Beinecke, et al., 1996) and the Massachusetts Group Insurance Commission (Huskamp, 1997; Ma and McGuire, 1998; Merrick, 1997). In this case, a carve-out eliminates a traditional indemnity plan for behavioral health care, ensuring that all behavioral health care will be managed. The payer also intervenes in the competitive process by preventing the traditional plan from competing on the basis of the behavioral health benefit (or other service carve-outs).

The payer may entirely remove the carved-out service from the market for competing (otherwise) integrated health plans. Figure 2 shows the case where enrollees choose among competing health plans for all of their healthcare except for the carved-out service. Behavioral healthcare for the State of Ohio employees and for employees and dependents of Pacific Bell are organized in such a fashion (Goldman, McColloch, and Sturm, 1998). Enrollees are not given a choice of plan for the carved out service, although a payer would typically use a competitive process to choose the carve-out vendor.

The third major form of carve-out arrangement is illustrated by Figure 3. In this case, enrollees have a choice of health plan for all services. Health plans choose to manage certain services such as mental health or cancer care by sub-contracting with a specialized managed care 
organization. In this case, the carve-out is an element of the competitive strategy adopted by a health plan. The payer may set general requirements for plans to meet, but does not specify organizational form. For example, an employer might contract with the Prudential HMO in St. Louis, which in turn carves out MH/SA to Merit Behavioral Health, Inc.

At present, mental health carve-out contracts are a rapidly growing feature of health insurance. According to Oss (1997), approximately 53 million people are enrolled in carve-out programs of all types. Between 20 and 25 million people are enrolled in so-called risk-based carve-out contracts (whereby the carve-out vendor assumes some or all of the financial risk for claims), which account for about $60 \%$ of the total revenue of firms that manage MHSA benefits. Carve-outs are more common among larger firms than smaller firms. Umland (1995) reports that $35 \%$ of employers with 5,000 or more employees were contracting with a specialty MHSA carveout vendor compared with a rate of about $3 \%$ for firms with fewer than 500 employees.

Carve-outs are an important new institutional feature in mental health and substance abuse. Although carve-outs exist for other conditions, they are most common in the care of MH/SA. To understand why carve-outs are part of the MH/SA landscape and what their effects are, we need to turn to issues of moral hazard and adverse selection covered in the next two sections.

\section{Private Insurance Markets, Moral Hazard, and Mental Health Care}

Private insurance markets have long offered insurance for mental health coverage on much more limited terms than for general health care coverage. Most Americans who obtain health insurance coverage through their employers have some coverage for mental health and substance abuse treatment, but it is rarely on the same terms as for other medical care. Over $90 \%$ of all 
employees covered by employer sponsored health insurance have mental health coverage. This is true of employees of both large and small firms (BLS, 1996). ${ }^{9}$ In 1993, large employers offered insurance plans with more restrictive coverage for mental health care than other services $86 \%$ of the time for inpatient benefits and $97 \%$ of the time for outpatient benefits. The corresponding figures for small employers were $85 \%$ and $99 \%$ respectively. The 1993 data offer evidence suggesting an erosion in coverage from the 1980s (Buck and Umland, 1997). It is important to note that the mere fact that more health plans establish limits for MH/SA coverage that they did in previous years does not mean that financial protection is less overall. Establishing that would require a more complete consideration of the terms of coverage. Typically, private insurance limits the number of reimbursable days of inpatient mental health care to 30 , and the number of outpatient visits to between 20 and 30 . Outpatient care generally carries $50 \%$ cost sharing (in about 54\% of all policies). Lifetime spending limits are common for both inpatient and outpatient mental health care (in $40 \%$ of health plans). ${ }^{10}$ The upper limit on plan cost sharing is usually defined as a limit on reimbursable visits or plan spending. ${ }^{11}$

In sum, mental health and substance abuse insurance coverage provides some coverage for low ranges of spending but leaves households unprotected against more expensive and potentially financially ruinous treatment. It is these observations along with the history of stigmatization that have led mental health advocacy groups to focus so much effort on obtaining "parity" in the terms of benefit design in private insurance for $\mathrm{MH} / \mathrm{SA}$ and general medical care. The first principle of optimal insurance is that insurance ought to cover high-end expenses (where the marginal utility

\footnotetext{
${ }^{9}$ In 1993-94, 82\% of employees of large firms and 66\% of employees of small firms participated in employer sponsored health plans (Unpublished data from the Employee Benefit Survey of the BLS).

10 All data except the level of day and visit limits reported in this paragraph are from the Employee Benefit Survey of the BLS.
} 
of money is greater) (Arrow, 1963). A higher demand response for mental health might imply different cost sharing arrangements for mental health services in a "second best" world, but this does not explain the presence of coverage limits. Optimal insurance in principle would still imply better high-end coverage, a different pattern of coverage than what is observed. The traditional explanations for differences in coverage and apparent failures in the insurance market are moral hazard and adverse selection.

\section{A. Evidence of Moral Hazard}

Since the 1950s, coverage of treatment for mental illness under private insurance has been controversial because of perceptions that psychotherapy was discretionary and its use would be greatly affected by insurance (McGuire, 1981). Insurers argued that equal coverage for health and mental health services would create a "cost control" problem. The moral hazard argument for special treatment of mental health care is based on the proposition that demand response to insurance coverage for mental health services is greater than that of other medical services and therefore the welfare loss from coverage is larger while the risk spending benefits are similar (Pauly, 1968; Zeckhauser, 1970). During the 1960s and 1970s, the demand response of mental health services to the terms of insurance was studied by examining the experiences of large insured populations. The federal employees health benefit program was frequently studied because claims data were available for this population and because coverage under the Blue Cross/Blue Shield high option plan was quite generous (Reed, 1974; Von Korff and Kramer, 1978; Sharfstein and Hustead, 1978). Other large insured populations studies are summarized in Frank and McGuire (1986). These included the United Mine Workers, Blue Cross of Michigan and Massachusetts, Group Health of Puget Sound, the United Auto Workers Health Plan,

\footnotetext{
${ }^{11}$ In 1996, Congress passed a so-called mental health parity law requiring dollar limits on mental health coverage
} 
CHAMPUS and the State of Washington employees among others. The empirical problem of separating adverse selection effects (persons more likely to use coverage choose better coverage) from the moral hazard problem (better coverage leads to demand response) was not addressed in this early work.

In the 1980s a number of econometric analyses made use of cross sectional surveys to investigate the magnitude of demand response for ambulatory mental health services, the services thought to be most responsive to cost sharing (McGuire, 1981; Horgan, 1986; Taube, Kessler and Burns, 1986; Watts, Scheffler and Jewell, 1986). ${ }^{12}$ This first generation of econometric models focused on estimating the demand response of ambulatory mental health care use to differences in the cost-sharing provisions across private insurance plans. The empirical models of demand were built on simple assumptions about the price schedule and consumer expectations (Manning and Frank, 1992). Annual number of visits (or dollars) were assumed to be the relevant decision unit, consumers were assumed to face a constant price. Consumers formulated their demand at the beginning of the annual decision-period. Insurance coverage for mental health is rarely described by a single price block, such as constant $50 \%$ coinsurance. Much more frequently there are two or even three blocks. Figure 4 shows a three-block schedule that would result from a deductible, a covered region and a limit on coverage. Empirical studies during the 1980s used an "average" price, and related this to quantity used. The block structure of pricing builds in a relation between use and average price unrelated to demand response (e.g., with a declining block price, average price and use are negatively correlated). In principle, instrumental variables might deal with this, but this is a highly imperfect way to address this measurement issue.

to be the same as for other conditions. Visit and day limits remain permissible.

${ }^{12}$ There is a more limited literature on the demand for inpatient psychiatric care. See, for example, Scheffler and Watts (1986). 
The models estimated during the 1980's under a variety of approaches to measuring outof- pocket costs were so-called two part models of demand (Manning et al., 1981). In the first part, the impact of cost sharing on the probability that an individual would use any mental health services was estimated using a logit or a probit model. The second part estimated the effect of cost sharing on the level of utilization (often subject to a logarithmic transformation) of mental health care conditional on some use of services. The second stage was usually estimated using ordinary least squares. The first generation of econometric research resulted in similar findings across studies: that ambulatory mental health services were highly responsive to cost sharing. Studies generally could not make a direct comparison to responsiveness in health care, but they typically arrived at a conclusion that demand for ambulatory mental health care was more responsive to cost sharing than ambulatory medical services. Those results were based on nonexperimental assignment of individuals to insurance plans, and were subject to selection problems. ${ }^{13}$ Contending with the bias introduced by selection of insurance condition in general health as well as mental health was a primary rationale for mounting the RAND Health Insurance Experiment (HIE).

The RAND HIE improved upon earlier studies of demand response by randomly assigning families to insurance conditions, minimizing the problems of the correlation of insurance and use introduced by unobserved variables. Over and above this central virtue of an experimental design, the HIE made dramatic improvements in the measurement of key variables that plagued earlier studies. Rather than relying on patient or provider reports about use, the HIE (RAND functioning as a third-party payer) directly observed what was used and when. Prices charged and paid were also directly observed, obviating the need to use the self-reported ranges and averages

\footnotetext{
13 McGuire (1981) used an instrumental variable approach to correct for endogenous insurance coverage. Other
} 
from earlier work. Finally, measures of health and mental health status, along with other covariates likely to influence demand, were measured much better in the HIE.

Random assignment and better measurement were great helps, but the problems introduced by the non-constant price schedules described by Figure 4 remained. Every HIE plan included a stop loss that limited a family's out-of-pocket spending to $\$ 1,000$ or less. A family in a $50 \%$ plan with a $\$ 750$ stop loss would, for example, have all care completely paid for, once they spent $\$ 1,500$ during a year. A family with any high cost treatment early in a year, or any foreseeable treatment (such as long-term psychotherapy) would rationally treat the marginal price of care as free, just like a family in the free care plan. Interpreting differences in use between the $50 \%$ plan and the free care plan, as well as other plans, requires confronting the issue of family's expectations about spending.

Data collection for the HIE took place in the mid-1970s. Early empirical work on the HIE (Newhouse et al., 1981; Manning et al., 1986, Wells et al., 1982) compared plans on the basis of "plan response" coinsurance only, for example users in the $50 \%$ plan to the free care plan. This does not yield a simple price elasticity estimate because the price change is averaged over stop losses. Later research also dealt explicitly with expectations, which the omnibus response to plan treated only implicitly. With the addition of some structural assumptions about how expectations were formed, estimates of the demand response could be derived.

Keeler, Manning, and Wells (1988) examined the demand of a subset of users in the RAND HIE who began mental health (or general health) treatment while far away (in dollar terms) from the limit on out-of-pocket expenses. They assumed that individuals would foresee, at the initiation of care, all the care that would eventually be used in a given episode of care, but that 
individuals did not foresee that they might exceed the out-of-pocket limit from other episodes. They show individuals in families with full insurance (free care) coverage used about four times more ambulatory mental health care than do those with virtually no coverage (95\% cost sharing). This is roughly double the response reported using a similar methodology for ambulatory medical care. Research on other data dealt with the issue of block pricing and demand. Ellis (1986) proposed an empirical approach which builds on the model developed by Keeler, Newhouse and Phelps (1977). He studied a mental health benefit where there was an increasing block price (no deductible, cost sharing up to a limit on outpatient spending). Ellis assumed that consumers would base consumption decisions on their "expected" end of year price. Ellis and McGuire (1986) applied this model to estimate price elasticities of demand. This research also showed mental health services to be relatively price elastic. In sum, nearly all the available evidence, experimental or observational, points in the direction of greater price response for ambulatory mental health than other health care services.

Table 3 summarizes the cumulative evidence on the demand response of ambulatory mental health services to cost sharing provisions in insurance. Note that the magnitudes of the price responses vary considerably. The relative response compared to ambulatory medical care is, however, quite consistent when comparison was possible. For example, Taube and colleagues (1986), using the NMCUES survey, report price elasticity estimates for mental health care that are four times those estimated for general ambulatory health care. Similarly, Horgan (1986) obtained elasticity estimates from the NMCES data set for mental health care that were 2.75 times those for ambulatory medical care. The relative elasticity estimate for mental health and medical care found in the RAND HIE was 2.66. The main policy implication of the empirical literature on the demand response of ambulatory mental health care to cost sharing is that there is an efficiency 
rationale for psychotherapy (the predominant form of ambulatory treatment) to be covered at a higher level of cost sharing than other types of ambulatory health care. Thus, in the absence of other forms of rationing or cost control, the strong evidence showing relatively high demand response implies higher cost sharing for psychotherapy. ${ }^{14}$ Based on the empirical results from the HIE (and some assumptions about risk aversion), Manning and Marquis (1992) estimate that 50\% cost sharing for psychotherapy is optimal (second best).

The moral hazard issue continues to be debated in the context of managed care (Scheffler et al, 1993). While there exists a growing body of research showing that managed care arrangements result in substantial savings in mental health and substance abuse (together referred to as behavioral health) spending paid through insurance, this evidence pertains primarily to the effect of "managed care" on levels of spending, not the response of spending to the terms of coverage (Christianson et al., 1995; Goldman, McCulloch and Sturm, 1997; Ma and McGuire, 1997; Calahan et al., 1995; Brisson et al., 1997). Demand response in managed care is an important area for study. The reason the subject of demand response must be looked at afresh is that the control of moral hazard in managed in managed care is done with other mechanisms in addition to demand-side cost sharing.

\section{B. Rationing in Managed Care}

Assessing the cost control or moral hazard problem in the context of managed care requires one to change the conceptions of rationing that have been employed in studying fee-forservice and indemnity insurance arrangements. Managed care in general and managed behavioral health care (MBHC) in particular address the moral hazard problem with tactics that ration care without relying on money prices paid by the consumer (Mechanic, Schlesinger, and McAlpine,

\footnotetext{
${ }^{14}$ This conclusion follows if a consumer demand curve is given a normative interpretation as a marginal benefit
} 
1995). Managed behavioral health care organizations (MBHO) must often allocate treatment resources subject to a prospectively set budget for serving a defined number of people. Features of rationing within managed behavioral health care organizations include:

- Establishment of a network of selected providers to furnish specialized services to a defined population of enrollees.

- Directing individuals to levels of care (e.g. inpatient hospital, residential, outpatient) based on clinical criteria about appropriate matches of clinical circumstances and provider capabilities.

- Writing contracts to providers that include financial incentives to limit care.

- Application of concepts of medical necessity to determine the need and benefits from continuing treatment at differing levels of care.

- Feedback of information to clinicians on treatment patterns relative to peers and clinical norms.

The MBHO makes these rationing choices in the context of either: a) markets where potential enrollees may choose among health plans based on quality indicators, price and other aspects of reputation and/or b) regulatory standards set by payers that require health plans to achieve certain specified levels of performance. ${ }^{15}$ From the very beginning of research on the economics of health insurance (e.g. Pauly, 1968), when the moral hazard problem was addressed exclusively by demand-side cost sharing, it was assumed that rationing took place in an economically rational fashion. As a price was introduced, the units of quantity that were "rationed out" were those that were the least valuable to the consumers. Consumers/patients were assumed to be utility-maximizing price takers in the face of the prices presented to them by their insurance coverage, implying that the consumer could buy as little or as much health care as he or she wished at the going price, and did so to maximize utility. The validity of these

schedule.

${ }^{15}$ For example, it is common to find employers requiring MBHOs to achieve certain access standards, to facilitate entry into treatment and to leave patients largely satisfied with the treatment process (see IOM, 1997). 
assumptions have, of course, generated thousands of academic journal pages. For example, Rice (1998) has argued that the rationing mechanism economists employ is not correct in a positive or descriptive sense, in that low value units are not necessarily those rationed out after prices rise.

With managed care, the assumption of the price-taking consumer can no longer be maintained. The essence of managed care - its very rationale - is the ability to ration care without imposing financial risk on consumers. Whatever one's view on the workability of the assumption of price-taking consumers in times gone by ${ }^{16}$ rationing by price-taking consumers certainly is indefensible in a health plan with managed care. Recent research on the economics of managed care has begun to characterize rationing within managed care, working along two tracks in modeling the effect of managed care. One approach views managed care organizations as setting quantities for individuals who may be heterogeneous with respect to severity of illness and demand (Baumgardner, 1991; Glazer and McGuire, 1998; Pauly and Ramsey, 1997). This approach views managed care as specifying what a person, given a demand curve, would get in terms of services under managed care. Note that if heteregeneous patients get the same quantity of services, managed care rations in an inefficient manner. In this case, shifting resources from consumers with low valuation to those with high valuation could improve welfare. A second line of research proposes that managed care organizations, ration by "shadow prices" (Keeler, Carter and Newhouse, 1998; Frank, Glazer, and McGuire, 1998). In this approach, it is "as if" consumers were charged a price, and the managed care plan gave them all services that were valued above the shadow price and denied care for all uses for which the value was below the shadow price. In this characterization of managed care the shadow price determines a "need" or benefit threshold that a patient must attain in order to qualify for treatment. Rationing by shadow

\footnotetext{
${ }^{16}$ See McGuire (1998) for discussion of the price-taking assumption in health care markets.
} 
prices is efficient in the sense that this form of rationing analyzes the marginal benefit of services to all users.

The fact that managed care rations without demand prices has important implications for the discussion of "parity" for mental health coverage and generally for the efficiency of benefit designs for mental health versus general medical care. In our discussion of moral hazard above we noted that the empirical evidence showing greater demand response to cost sharing for mental health care relative to general medical care in the context of fee-for-service-indemnity insurance arrangements implies that it would be efficient to cover ambulatory mental health care differently from general health care. This is an argument against parity for MH/SA. Normative conclusions about coverage change are altered under managed care. For example, Ramsey and Pauly (1998) consider the roles for quantity-type managed care rationing and demand-side cost sharing in a model in which quantity received by the consumer is the minimum of what would be demanded, or what the managed care firm would supply. They are concerned with the optimal combination of the two rationing instruments. Some quantity rationing is always part of the optimal policy, and it is unclear how different demand responses fit into the story.

In the case in which rationing is only by shadow prices, we can show clearly the potentially major impact of superimposing a new rationing mechanism for quantity determination. In this case, the higher demand elasticity of mental health services does not imply a higher shadow price, where this form of rationing is used, is in contrast to the usual optimal insurance result. We first consider the problem diagrammatically. Figures $5 \mathrm{a}$ and $5 \mathrm{~b}$ characterize the demand curves for general medical care and mental health care in accord with empirical findings from the literature. The demand for mental health services is more price elastic than is the demand for 
medical care. We begin by imposing a shadow price of $\mathrm{q}$ to ration both types of services. At this initial shadow price the managed care plan would provide $\mathrm{g}$ dollars in general medical care spending and $\mathrm{m}$ dollars of mental health care for an individual with these two demand curves. If we increase the shadow price to q' for both areas of care, which represents stricter rationing, the result is g' and m' levels of spending on general medical and mental health care, respectively. The higher elasticity for mental health services means that the cut back in services for mental health will be greater than that in other service areas.

The efficiency implications of a change in shadow price under managed care are quite different from comparable changes in benefit design under indemnity insurance. Because the shadow price is an "as if" price consumers do not actually bear more financial risk when it rises. There is no risk/inefficiency trade-off taking place to determine the optimal shadow price. The only efficiency issue is the allocation of resources between health care and mental health care, which is done efficiently when the shadow prices are equal, irrespective of the relative demand responses.

This can be shown more formally within a model that will first be used to define efficient rationing, and later be used to compare efficient rationing with that which may occur in the presence of selection incentives. ${ }^{17}$ Consider a planner seeking to maximize net benefits subject to a budget, for a given set of enrollees in a plan. The planner chooses the level of rationing $\mathrm{q}_{\mathrm{s}}$, for each of s services. Each service quantity is expressed in dollars, assuming price is normalized to \$1. Use of each service for each enrollee is a function of its own shadow price only.

\footnotetext{
${ }^{17}$ The discussion in this section has benefited greatly from extensive discussions with Jacob Gazer and is closely related to the discussion in Frank, Glazer and McGuire (1998).
} 
Specifically, suppose a plan has a membership consisting of $\mathrm{N}_{\mathrm{t}}$ members of type $\mathrm{t}$, $\sum_{\mathrm{t}} \mathrm{N}_{\mathrm{t}}=\mathrm{N}$, where a type of person corresponds to a valuation that person places on health care services. Person of type $t$ has a benefit function $B_{t}\left(m_{1 t}\left(q_{1}\right), m_{2 t}\left(q_{2}\right) \ldots m_{s t}\left(q_{s}\right)\right)$, where $q_{s}$ is the shadow price for service $\mathrm{s}$ and $\mathrm{m}_{\mathrm{st}}\left(\mathrm{q}_{\mathrm{s}}\right)$ is the spending type $\mathrm{t}$ can expect if the shadow price is $\mathrm{q}_{\mathrm{s}}{ }^{18}$ Note that $\mathrm{q}_{\mathrm{s}}$ is set in common for all users of service s. What each person gets is dependent on their "need" or marginal benefit. Then $\mathrm{B}_{\mathrm{t}}(\bullet)$ is the person's valuation of all the elements of expected spending. With this notation, total benefits to all enrollees are

$$
\sum_{\mathrm{t}} \mathrm{N}_{\mathrm{t}} \mathrm{B}_{\mathrm{t}}\left(\mathrm{m}_{1 \mathrm{t}}\left(\mathrm{q}_{1}\right), \mathrm{m}_{2 \mathrm{t}}\left(\mathrm{q}_{2}\right) \ldots \mathrm{m}_{\mathrm{st}}\left(\mathrm{q}_{\mathrm{s}}\right)\right)
$$

with a total cost of

$$
\sum_{\mathrm{t}} \mathrm{N}_{\mathrm{t}}\left(\sum_{\mathrm{s}} \mathrm{m}_{\mathrm{st}}\left(\mathrm{q}_{\mathrm{s}}\right)\right)
$$

Maximizing benefits less costs with respect to each $\mathrm{q}_{\mathrm{s}}$ implies,

$$
\sum_{\mathrm{t}} \mathrm{N}_{\mathrm{t}}\left(\mathrm{B}_{\mathrm{ts}} \mathrm{m}_{\mathrm{st}}^{\prime}-\mathrm{m}_{\mathrm{st}}^{\prime}\right)=0 \quad \forall \mathrm{s}
$$

$\mathrm{B}_{\mathrm{ts}}$ is the derivative of $\mathrm{B}_{\mathrm{t}}(\bullet)$ with respect to the $\mathrm{s}^{\text {th }}$ argument, and $\mathrm{m}_{\mathrm{st}}^{\prime}=\frac{\mathrm{dm}_{\mathrm{st}}\left(\mathrm{q}_{\mathrm{s}}\right)}{\mathrm{dq}_{\mathrm{s}}}$

Rewriting (3) yields,

$$
\sum_{\mathrm{t}} \mathrm{N}_{\mathrm{t}} \mathrm{B}_{\mathrm{ts}} \mathrm{m}_{\mathrm{st}}^{\prime}=\sum_{\mathrm{t}} \mathrm{N}_{\mathrm{t}} \mathrm{m}_{\mathrm{st}}^{\prime}, \text { or } \frac{\sum \mathrm{N}_{\mathrm{t}} \mathrm{B}_{\mathrm{ts}}}{\mathrm{N}}=1
$$

Since rationing by shadow price implies $B_{t s}$ is the same for all types, (4) implies that

$$
\mathrm{B}_{\mathrm{ts}}=1 \quad \forall_{\mathrm{s}}
$$

\footnotetext{
${ }^{18}$ Consumers value spending on the various services. Spending is determined by the shadow-price rationing and expressed as $\mathrm{m}_{\mathrm{st}}\left(\mathrm{q}_{\mathrm{s}}\right)$. Diagramatically, the relation between $\mathrm{q}$ and spending can be seen in Figure 5 .
} 
All shadow prices should be set equal to one. All services would be subject to the same level of rationing and that every dollar of spending would generate at least a dollar in health care benefits. The implication of the first best is that the managed care organization should have a budget sufficient to cover the costs of all services implied by the efficient level of rationing.

It should be recognized that the condition given in equation (4) is based on the assumption that the demand response for a service (e.g. cardiac care) is the same for each person in the patient type category t. The demand response may, of course, vary across services within a patient type category. This will be important for the selection analyses presented in Section IV.C.

This normative problem could be transformed into a second-best analysis by maximizing the value of spending to the members of the plan subject to a given budget, rather than maximizing benefits less cost. The second-best analysis is more general and covers the case in which the goal is to maximize welfare subject to given levels of public funds or perhaps a set of capitation payments. It is straightforward to show that the result in (4') is altered so that the marginal benefit of spending in all services will be equalized to a new shadow price, the value of the marginal dollar given the budget. This shadow price is one, of course, at the first-best level of spending. It is above (below) one when the health budget is set below (above) the first-best level.

Two points flow from this analysis that are important for the economics of mental health. First, if managed care rations by shadow price, and does so efficiently, providing full coverage (parity) for mental health services can improve efficiency by increasing financial protection with no additional loss due to moral hazard, a point that has been anticipated in some policy discussions (Frank, Koyanagi and McGuire, 1997; National Advisory Mental Health Council, 1997; Sturm, 1997). Second, efficient rationing implies rationing equally across service areas, in the sense of setting the same shadow price across services. Efficiency conditions imply equality in 
shadow prices irrespective of demand elasticities. (Note that the demand-response term, $\mathrm{m}_{\mathrm{st}}^{\prime}$, drops out of (4).)

The normative implications of this model of rationing are parallel to those that underlie models used in cost-effectiveness analysis (Weinstein, 1995). The manner in which costeffectiveness information has been proposed for use in resource allocation is consistent with the simple model proposed above. Weinstein and Zeckhauser (1972) propose an approach to efficient rationing within a budget using estimates of Quality Adjusted Life Years (QALYs) derived from specific health programs. QALYs were initially designed as a means of developing a common metric for evaluating heterogeneous health outcomes in a fashion which takes account of individual preferences for different health states (see Kaplan, 1995 for a review). While that work focuses on rank ordering health treatment programs in terms of the QALYs they yield in order to find the incremental intervention, the point here is that budget allocation process across classes of "incremental" interventions should allocate funds so that the health benefit per dollar (perhaps as measured by QALYs) is equal. ${ }^{19}$

In the analysis just conducted, we have assumed that shadow prices were the only rationing device, whereas, in fact, demand-side price rationing is likely to be going on at the same time. A short-side model in which utilization is the minimum of demand and supply is the approach noted above by Pauly and Ramsey. Another is a bargaining model in which utilization is a compromise between what the patient wants at the price he or she pays and what the seller wants to supply given the incentives and constraints it faces (Ellis and McGuire, 1990). Any

\footnotetext{
${ }^{19}$ The analysis would be altered if we assumed, Baumgardner-like, that managed care plans ration by quantity setting, instead of assuming, Keeler, Carter, and Newhouse-like, that plans ration by a shadow price. Maximization of benefits less costs with respect to $\mathrm{m}_{\mathrm{s}}$ with the implied constraint that $\mathrm{m}_{\mathrm{st}}=\mathrm{m}_{\mathrm{s}}$ for all $\mathrm{t}$ yields a public-goods like condition in (4). The weighted marginal benefits must be equalized across services. In this altered analysis, the "expected" marginal benefits are equalized across services.
} 
supply-side instrument will have the virtue that rationing is being accomplished without imposing financial risk on consumers, and, therefore, is likely to be used "first" in putting together an optimal payment system (Ellis and McGuire, 1993). Supply-side policies, especially "one size fits all" types, may run the risk of not respecting consumer preferences. Pauly and Ramsey's (1998) approach suggests one way to capture this. Supply side policies also do not address initial visits very well. The literature in health economics on optimal combinations of demand and supply-side policies is thin, and reasonable incorporation of managed care tactics in normative models is only beginning (Ma and McGuire, 1997).

Considerations of optimal payment systems in mental health encounter the same issues about patient and provider motivation as do such discussions in the general field of health economics. The assumption of rational, utility-maximizing, price-taking consumers with fixed preferences seems, if anything, less convincing in demand for mental health care than for general health.

Interpretation of Demand: The normative interpretation of mental health care demand in the fee-for-service indemnity insurance world has long been problematic. Long standing issues of asymmetric information and imperfect agency relationships that were noted early in the study of health care markets (Arrow, 1963) temper the normative interpretation of all health care demand functions as marginal benefit schedules. The demand for mental health care has a special set of constraints on consumer information. Demand for mental health services may be influenced by fear of stigma, Veblen's "bandwagon" effects (McGuire, 1981) and unclear information about efficacy of specific treatments. In addition, many mental disorders affect the capacity of individuals to make decisions in their own best interests (Rubin, 1978). For these illnesses, placing a strong normative interpretation on observed demand behavior is unlikely to be justified. 
The relation between behavior and normative marginal benefit schedules under managed care arrangements may differ from that in fee-for-service indemnity insurance for many reasons related to new forms of rationing, including creation of managed care provider networks, using payment systems that depart from simple fee-for-service arrangements, and the use of utilization management techniques and information feedback. Managed care also may alter the traditional agency relationships between patient and clinician (Blomquist, 1991; Mechanic, 1998). Providers seeking to be part of a managed care network must balance patient, managed care organization, and their own economic interest differently than under FFS. If provider actions influence demand, the relationship between demand-side price and quantity consumed must be constructed with a whole new set of factors in the ceterus paribus under managed care. In general, since managed care mechanisms are intended to affect rationing, we can expect that the positive demand curve will change. Conducting research on these changes is an important element of the current research agenda in mental health, as well as in health services.

We can speculate about what changes we might expect in demand behavior. If forces to ration care in addition to demand-side prices are in play, the change in quantity utilized with respect to a change in price is probably smaller. This emerges from a short-side model (Pauly and Ramsey, 1998), because some price changes for some consumers do not affect quantity since the supply constraint is binding. It would also emerge from a bargaining model because the quantity used is a compromise, and even if "desired demand" changes by the same amount, actual use is a weighted average of desired demand and desired supply (which does not change). Thus, here too, alternative rationing dampens demand response.

The normative view of such changes must be approached cautiously for reasons stated above. Nevertheless, at the very least the "cost control problem" that has been of such a central 
concern in mental health policy is potentially attenuated with managed care. The welfare loss from equal coverage, or parity, would also likely be reduced.

\section{Managed Care, Supply Side Incentives and Moral Hazard: Evidence}

Alternative methods of organizing and paying for mental health and substance abuse services within private insurance, Medicaid and Medicare have received increasing attention from researchers and policy makers in the U.S. since the mid-1980s. Similarly, Britain has recently begun to use supply side incentives to affect resource allocation in the primary care and specialty mental health sectors (Knapp, 1997). To date most of the evidence on the impact of payment and organizational arrangements on utilization is based on the U.S. experience.

Research and policy debates about supply side payment incentives have primarily been focused on hospital and health plan payment schemes. Prior to the mid-1980s payments by insurers in the U.S. were commonly made on the basis of retrospectively incurred costs or charges for hospital care and charges or customary fees for professional services (IOM, 1995). Since the mid-1980s payments have increasingly been made prospectively and are based on days or discharges for hospitals and on a per capita basis for health plans and groups of health care professionals.

Prospective payment systems were introduced in order to give providers incentives to control costs. The basic idea is to separate the level of payment, determined prospectively, from the costs the provider incurs. In practice, payment systems are not always completely prospective, and may include some features, which, at least partially, reimburse costs. In Medicare's Prospective Payment System for hospital discharges, there are outlier features for

some costs. Medicare's TEFRA system for paying psychiatric hospitals and psychiatric units of general hospitals has explicit features that increase payments if a facility's cost rises above a 
certain level (Cromwell et al., 1992). State payment systems for Medicaid may include rebasing features which, in effect, reimburse part of costs. To capture elements of prospective and retrospective payment that characterize actual payment systems, we can characterize a general payment system in the following way:

$$
P=\alpha+\beta C
$$

where $\alpha$ is the prospective portion of payment that is unrelated to incurred costs and can be paid in connection to any of the above mentioned units of payment (days, cases, per capita); $\beta$ is what has been referred to as the supply side cost sharing parameter (Ellis and McGuire, 1986; Newhouse, 1996) indicating the portion of incurred costs, C, that are reimbursed in the payment system. Cost based reimbursement can be characterized by setting $\alpha=0$ and $\beta=1$. A pure form of per case prospective payment for hospitals (similar to Medicare's Prospective Payment System or PPS) pays on the basis of admissions to hospitals, sets $\alpha=$ the average cost of a case, and $\beta=$ $0 .{ }^{20} \mathrm{~A}$ "mixed" system is in the general case, where $\alpha>0$ and $0<\beta<1$. One can use this categorization for contracts to managed care organizations. Under managed care arrangements in the mental health and substance abuse area there are three dominant approaches to payment, all based on the cost of care per capita for a defined population: pure capitation where the per capita payment is set such that $\alpha=$ the average $\mathrm{MH} / \mathrm{SA}$ costs per enrollee, and $\beta=0$; mixed payment or soft capitation where $\alpha>0$ and $0<\beta<1$; and Administrative Services Only (ASO) contracts where claims are reimbursed on a fee-for-services basis but the managed care organization is judged and contract renewal is related to its performance in controlling spending.

\footnotetext{
${ }^{20}$ The average cost is typically based on actual costs in a previous year and is usually adjusted for the case mix of the users of the service. Case mix will be discussed in the context of risk adjusted capitation rates below.
} 
Representation of payment systems with a prospective and retrospective component, in a mixed system, has also been useful in research on "optimal payment systems," which may feature only partial supply side cost sharing (with $0<\beta<1$ ) for reasons of agency (Ellis and McGuire, 1986), or information issues (Newhouse, 1996). ${ }^{21}$

1. Research on Hospital Payment Systems: The impact of payment arrangements on inpatient psychiatric care has been the subject of many studies. ${ }^{22}$ Analyses of natural experiments within Medicare, Medicaid and several states which regulated hospital payments have formed the foundation for the research. In Medicaid, indicated that there were strong responses to various forms of prospective payment relative to cost based reimbursement (Frank and Lave 1989; Lave and Frank, 1990). Studies of Medicaid also suggest that the responses to per case prospective payments appear to be more complex than one might have expected. For example, relative to cost-based payment fewer psychiatric patients paid under per case prospective payment had very short hospital stays (1 to 10 days) and fewer also had long stays (over 30 days) resulting in a lower average length of stay under prospective payment. Ellis and McGuire (1995) using data from the state of New Hampshire found hospitals respond both to the level of payment (" $\alpha$ ") in terms of quality competition, as well as to the degree of supply-side cost sharing (" $\beta$ ").

Studies in Medicare used implementation of the PPS quantify general hospital response to the new payment arrangement (Frank et al., 1987; Freiman et al., 1989; Lave et al., 1988). ${ }^{23}$ The estimated impacts of the new payment system showed length of stay reductions for inpatient psychiatric care in the range of $17 \%$ to $25 \%$. The estimated effects of the initial implementation

\footnotetext{
${ }^{21}$ The average cost is typically based on actual costs in a previous year adjusted for inflation and is usually adjusted for the case mix of the users of the service. Case mix will be discussed in the context of risk adjusted capitation rates below.

${ }^{22}$ See Harrow and Ellis (1992) for a review of the early literature.

${ }^{23}$ Most specialty mental health providers were exempt from PPS and paid under the mixed system, TEFRA.
} 
of PPS for general medical care was to reduce length of stay by between $9 \%$ and $12 \%$ (PROPAC, 1986).

Several states implemented all-payer rate setting programs in the 1970s and 1980s in an effort to control hospital costs. Rupp, Steinwachs and Salkever (1984) examined the impact of the per case prospective payment method introduced in Maryland, finding evidence for decreases in length of stay, and increases in re-admission rates. Frank and Jackson (1989) studied the introduction of prospectively set hospital budgets $(\alpha=$ historical budget adjusted for general inflation and $\beta=0$ ) in two regions of New York State during the 1980s. Compared to "control" hospitals paid using a prospectively set per diem payment, prospectively set budgets led to reduced admissions of between $16 \%$ and $22 \%$.

In summary the evidence from the application of prospective payment methods to hospitals suggests strong hospital responses to incentives to reduce costs and utilization of psychiatric services.

2. Research on Managed Care and Capitation: The general form of a contract as a "mixed system" contract can be applied to capitation and managed care. Figure 6 illustrates forms of contracts that are based on capitation arrangements that are commonly found in connection with managed behavioral health contracts. The horizontal axis measures actual costs incurred by the managed care organization. The vertical axis measures payments made to the managed care organization. The $45^{0}$ line represents cost based reimbursement, that is payments equal incurred costs. The horizontal line at $\mathrm{C}$ represents "pure" capitation $(\alpha=\mathrm{C}$ and $\beta=0)$. The managed care organization bears $100 \%$ of the financial risk for incurred costs per enrollee. For managing care of a population at spending levels to the left of $\mathrm{T}$ the managed care organization collects a profit equal to the vertical distance between the line at $\mathrm{C}$ and the 45 degree line. If spending exceeds $\mathrm{T}$ 
the managed care organization incurs a loss equal to the vertical distance between the line at $\mathrm{C}$ and the $45^{\circ}$ line. The financial incentive to restrain spending is clear. Most HMOs and some carve-out programs use this type of payment arrangement.

The line NEB represents a mixed or soft capitation payment system. Under these types of arrangements the payer sets a capitation target at $\mathrm{T}$. Thus, if the managed care organization incurs costs per enrollee equal to $\mathrm{T}$ it will break even. If the managed care organization incurs costs between points $\mathrm{L}$ and $\mathrm{M}$ on Figure 6, payer and the managed care organization will share the profit or loss according to the slope of the line segment EB (or $\beta$ in our characterization of payment above). At levels of spending above $\mathrm{M}$ and below $\mathrm{L}$ the payers holds all the risk. Profit and losses are capped at spending level $\mathrm{L}$ and $\mathrm{M}$. This means that the managed care organization's maximum profit is EF and the maximum loss is AB. This is illustrated in Figure 6 by the fact that line segment NE is parallel to the $45^{\circ}$ line. Under the soft capitation payment method there are incentives to reduce spending but they are weaker because the link between payment and incurred costs has not been fully severed $(\beta>0)$. One rationale for such arrangements is concern that managed care organizations may "over manage" the mental health benefit (possibly due to selection incentives discussed below). A second rationale relates to the fact that most payers are large relative to specialty managed behavioral care organizations and thus are in a better position to bear risk.

\section{2a. Evidence: The Early Experiences}

Risk contracting for managed mental health care predates the specialty industry of managed behavioral health care (MBHC). Prepaid group practices and health maintenance organizations (HMOs) have accepted risk contracts for MH/SA services, along with other health care, for many years. In general, these contracts are capitation contracts in which all the cost or 
claims risk is born by the prepaid group. As part of the Health Insurance Experiment (HIE), Manning and colleagues (1989) compared the cost and use of care by families assigned to a prepaid group practice, the Group Health Cooperative of Puget Sound, with that of families assigned to receive free care in the fee-for-service sector. Although enrollees with the two types of insurance sought care at the same rate, the fee-for-service population had mental health expenditure levels almost three times greater than enrollees in the prepaid health plan (\$69.70 vs. \$24.60 in 1977 dollars). Paula Diehr and colleagues compared the use of outpatient mental health care in a fee-for-service unmanaged benefit plan, a staff model HMO, and an individual practice association (IPA) prepaid plan for Washington State employees, with results that were consistent with Manning's (Diehr et al., 1984). However, because the Washington employees chose their plan and were not assigned to an insurance condition as in the Health Insurance Experiment, the Diehr findings may at least partly reflect differences in each study group's needs and not just an effect of the plan.

Prepaid groups can exert direct managerial authority over the supply of mental health services. Indeed, by controlling the number of therapist hours available, they can almost directly ration the volume of care to be provided. Managed behavioral health care companies, however, may have weaker incentives to reduce costs than prepaid groups do, and they typically have much less direct control over their contracted providers. Thus, the cost reductions from managed behavioral health care should be expected to be more modest than from prepaid groups.

The literature on specific MBHC programs is relatively recent. The initial experiences reported by employers include some instances of large reductions in the costs of MH/SA care. Hodgkin (1992) reviewed the early literature on the effects of utilization management, finding very few studies that offered evaluation methods that could produce convincing results. The lone 
study that was methodologically sound showed savings in the neighborhood of $10 \%$ to $15 \%$ on total claims costs, a faint indication of what was to come.

\section{2b. More Recent Evidence}

The CHAMPUS program experimented with an "at risk" PPO for behavioral health services during the late 1980s in the Tidewater, Virginia area. That area was known to be a high cost region with regard to $\mathrm{MH} / \mathrm{SA}$ outlays. The demonstration showed significant savings (about $31 \%$ below expected costs in the absence of the program) stemming largely from reduced use of inpatient care. In spite of the reported savings, there were clearly areas of considerable waste in expenditures and difficulties in effectively running the program (Coulam and Gaumer, 1990). ${ }^{24}$

A number of private corporations have adopted specialty MBHC carve-out programs. It is fairly common to see reports of reductions in claims costs of $40 \%$ to $50 \%$. The interpretation of these changes is, of course, quite difficult. Often, more than one change is made and attributing cause and effect is difficult. Within a plan, there can be considerable year-to-year variation for unknown reasons (Dickey and Azeni, 1992; McGuire, 1994). Finally, a version of the "file-drawer" problem in research may be at work; only "good" (read "publishable") experience may see the light.

\footnotetext{
${ }^{24}$ The CHAMPUS program has continued to experiment with managed care. The program is now subject to three differing forms of managed care arrangements. The National Utilization Management program works under a CHAMPUS contract with a specialty MBHC vendor to provide pre-admission certification and concurrent review on a nation wide basis. The contract with the MBHC vendor does not place the vendor at any financial risk related to utilization of MH/SA care. The CRI program under CHAMPUS is a fixed price "at risk" contract that is in place in Hawaii and California. Finally, the Tidewater CPA arrangement continues to be in operation. In recent years the CRI and the general MBHC arrangement have realized the largest reductions in costs. The Tidewater plan reported a small increase in costs. The absence of cost reductions in Tidewater during the 1989 to 1992 time period may be due to the substantial savings that were realized during the early years of the program. A 9\% increase over 4 years that was reported for the CRI program is quite small for any health plan during that time period.
} 
With these limitations in mind, we review the reports of the performance of Managed Behavioral Health Care (MBHC) carve-out programs. Key aspects of these studies are summarized on Table 4. As the Table indicates each of these natural experiments has taken place in the context of different institutional arrangements. Some carve-outs were implemented within State Medicaid (Massachusetts and Utah) programs while others in privately insured populations (the GIC and Pacific Bell). The risk sharing arrangements also varied considerably. In Utah a "pure" capitation contract was phased-in, while in Massachusetts, the GIC and Medicaid contracts shifted only a small amount of risk to the MBHC vendor. The Pacific Bell ASO contract involved no financial risk at all to the MBHC vendor.

Table 4 reports impressive reductions in mental health spending relative to fee-for-service arrangements (the comparison condition for all the studies). The estimated reductions in spending range from $-17 \%$ to $-43 \%$. The reductions for the most part took place in the context of programs that had historically experienced high levels of spending on mental health services, with the exception of the Utah study. While the observed savings across studies were in many respects achieved by similar shifts in services utilization patterns, there are some important differences. Savings were primarily realized by 1) reductions in use of inpatient hospital care (all studies), 2) reductions in nominal prices paid to providers (Goldman et al., 1998; Ma and McGuire, 1998; Callahan et al., 1995); and 3) reduced duration of outpatient treatment (Goldman et al 1998, Huskamp, 1997).

The studies in Table 4 reflect changes in rates of utilization of any mental health and substance abuse care for the insured populations. Important differences in the utilization patterns were observed across studies. The Massachusetts Medicaid experience saw an initial increase in use of behavioral health care following introduction of the carve-out program (Callahan et al., 
1995). After three years the increase in use had largely vanished (Frank, McGuire, Notman and Woodward, 1996). In the Pacific Bell study a significant increase in the percentage of enrollees using any behavioral health care was estimated (a 17\% rise). In contrast the Massachusetts GIC experienced very large reductions in the percentage of the population using behavioral health care ( $20 \%$ to $30 \%$ reductions). It is interesting to note that some companies such as SterlingWinthrop report dramatic increases in access to care (50\% increase in rates of utilization), due to expanded use of outpatient care, at the same time that claims cost were falling. Reductions in rates of use create concern because it may be indicative of reductions in access to care for individuals that may benefit substantially from treatment. Managed care programs are quite complicated and use many methods of rationing to control use. The studies discussed also reflect heterogeneous populations and differences in other institutional features. For this reason there are as yet no clear explanations for why the response to managed care arrangements might vary so strongly in terms of the percentage of the population using care.

Theory implies that the more high-powered incentives associated with pure capitation should lead to greater cost reductions in comparison to lower-powered incentives with risk sharing or ASO contracts. Sturm (1997) pointed out, this pattern has not materialized in the experience so far: large reductions have occurred even without high-powered incentives. The high/lower power of a contract is one dimension, but actual contracts can be quite complex, especially with regard to their dynamic incentives. The first Massachusetts Medicaid contract made a fixed payment for administrative costs (giving incentives not to spend on administration and managing care), weak incentives for cost reduction, and in some years ratchet effects which create a link between targets in future years and performance in past years (Frank and McGuire, 1997). A powerful incentive in this new and growing industry is what role contract performance 
will have on future business. This may be the dominant incentive with respect to all current contracts (Ma and McGuire, 1998), perhaps serving as an explanation of why large cost savings emerge in many forms of contracts. Relating experience to the form of the contract seems particularly treacherous on the basis of current data, given the rich set of incentives that are probably operative. Case studies are building an empirical base on which conclusions ultimately can be drawn.

Although much work remains to be done about the magnitude of savings that can be expected in particular circumstances and the connections between savings and contract features, it seems clear that managed care can substantially reduce costs in MH/SA. Some research has taken place on the quality impact of managed care. Generally, in comparing fee-for-service to capitated managed care plans does not reveal a uniform quality impact one way or another (Miller and Luft, 1997). In mental health, two studies have found that quality may be adversely affected in HMOstyle managed care (Wells, 1996; Lurie et al., 1992). Merrick (1997) studied the pattern of claims for persons hospitalized for major depression prior to and post the carve-out plan in the GIC plan noted above. Her results pointed to more appropriate patterns of care under the carve-out. Readmissions did not rise, and contact with outpatient providers following discharge improved under managed care.

There is as yet very little research on responses to differences in risk sharing arrangements across MBHC plans. Sorting out these explanations requires careful measurement of contractual features and market circumstances facing MBHC vendors. Thus, while there has been considerable progress in estimating the gross spending and utilization responses to MBHC contracts, we have a long way to go to understand the specific contractual and market mechanisms that generate such changes in the delivery of mental health and substance abuse care. 


\section{Insurance Markets, Adverse Selection and Mental Health Care}

The special effort needed to control moral hazard in MH/SA has been put forward as one reason why $\mathrm{MH} / \mathrm{SA}$ services are organized and paid for differently than other types of health care. Managed care represents a new set of institutions that appear to change the terms of Zeckhauser's (1970) dilemma, allowing moral hazard to be controlled without reduction in risk spreading (Mechanic, 1997). The speculation above that managed care can substitute for demand-side cost sharing as a cost control device would suggest that insurance coverage for MH/SA should improve with managed care, as the goal of risk spreading could be pursued with less moral hazard cost. Nevertheless, in the early and mid-1990s, when managed care was emerging, we observed two significant developments in insurance markets related to MH/SA. First, there was some evidence of erosion of insurance coverage for MH/SA (Buck and Umland, 1997). In particular, the portion of health plans which imposed tight limits on coverage of MH/SA care appears to have grown during the 1990s. This is puzzling given the rapid expansion of enrollment in managed care plans (PPRC, 1996). A second development has been the growth of specialized behavioral health carve-out programs (Frank, Huskamp, McGuire and Newhouse, 1996). Appearance of coverages and insurance arrangements more generally reflect the profit-driven considerations of adverse selection, as well as concerns for moral hazard. As in the case of moral hazard, evidence suggests that the forces of adverse selection may work more powerfully in mental health than in health care.

In the context of insurance coverage for mental health services, conventional wisdom is that high cost enrollees are attracted by relatively generous coverage provisions for mental health and substance abuse care. Competition among indemnity insurance plans may have resulted in 
inefficiently low levels of coverage for behavioral health care. This was the basis of argument in the 1980s that justified federal and state "mandated coverage" legislation requiring private insurance to cover minimum levels of mental health care (McGuire and Montgomery, 1982; Frank, 1989).

In the sections that follow, we review the evidence on selection in mental health and substance abuse, discuss the policy responses by government in the context of fee-for-service indemnity insurance contracts and then examine selection in the context of managed care. This discussion will point to explanations for the new institutional arrangements that are arising in the $\mathrm{MH} / \mathrm{SA}$ sub-sector.

\section{A. Evidence of Selection in MH/SA}

The Federal Employees Health Benefit Program (FEHBP) during the 1960's and 1970's provided an early example of how concerns about selection drove competing insurers to lower benefits for MH/SA services. Plans offering more generous benefits quickly attracted individuals who wanted to avail themselves of these services. The generous coverage of MH/SA lost viability as people not expecting to use services enrolled in plans with more limited coverage (Reed, 1974). Use of mental health care has been found to be two to three times higher in the Blue Cross/Blue Shield "high option" plan compared to the low option plan, even though the actual coverage differences are quite small (Padgett et al., 1993), implying that the differences in use were due to selection rather than demand response (moral hazard). Further evidence for adverse selection in the FEHBP comes from comparing responses to the price of MH/SA care under the FEHBP and The RAND Health Insurance Experiment (Newhouse et al., 1993). In the RAND experiment, individuals were randomly assigned to health insurance plans and the observed price response to differential coverage was substantially lower than what was observed in FEHBP 
(Newhouse et al., 1993). The differences in price response suggest that where plan choice was possible (under FEHBP), the "high option" (lower priced) plan differentially attracted poorer risks making it appear as if the plan with slightly more generous coverage induced much higher utilization of MH/SA care.

Adverse selection is an issue for all of health insurance, but may be especially serious in the mental health area. Deb, Rubin and Wilcox-Gok (1996) found that individuals with a family member with a mental illness were more likely than otherwise similar members of the U.S. population to choose coverage with more generous mental health care provisions. Sturm and his colleagues (1994) analyzed the treatment of depression across health plans as part of the Medical Outcomes Study (MOS), finding that depressed individuals receiving care from specialists were more likely to migrate from prepaid to fee-for-service plans. They also found that individuals switching from prepaid to fee-for-service plans were at risk for poorer outcomes. Ellis (1988) examined the persistence of spending over time and its implications for health plan choice. Individuals with a history of mental health care utilization had persistently higher levels of spending than did otherwise similar insured individuals. He also found that a history of mental health care utilization had a significant impact on an individual's choice of health plan. Higher levels of prior year mental health spending increases the likelihood that an enrollee chooses a low deductible plan. This suggests choice based on anticipated spending such that the expected deductible payments exceed the differences in plan premium differentials.

Perneger and colleagues (1995) found evidence of adverse selection related to mental health care in the context of insurance markets in Switzerland. They analyzed a situation where one indemnity plan among several health plans was changed to a managed care plan. The managed care plan introduced gatekeepers and limits on insurance coverage for psychiatric 
services. Those who remained in the indemnity plan made on average 2.3 more visits for mental health care in the previous year and were more likely to receive a prescription for a psychoactive medication than those who chose managed care.

Taken together, these results suggest that users of mental health care may have greater subsequent year health care spending than otherwise similar people, putting plans attracting mental health users at a financial disadvantage. Persistent levels of above-average spending for the individuals with severe mental disorders within the Medicaid program was recently reported by Kronick et al. (1996). In sum, there is both direct and indirect evidence suggesting that the mentally ill and substance abuse users are associated with higher levels of health care spending and that they systematically select health plans that offer more generous coverage for behavioral health treatment. Such behavior creates economic incentives for health plans to adopt strategies that will reduce their attractiveness to users of mental health care.

\section{B. Policy Responses to Selection: Fee-for-Service-Indemnity Contracts}

During the 1970s and 1980s competition to avoid "bad risks" was channeled into limiting coverage for treatment of mental and addictive disorders. Approximately 22 states counteracted adverse selection by mandated benefit statutes which specified minimum level of coverage for MH/SA care (McGuire and Montgomery, 1982; Frank, 1989). These statutes generally specified coverage minimums in terms of coinsurance, limits on outpatient visits and hospital days, and deductibles. Since benefit design features were the key provisions of an insurance contract determining coverage, regulation of these components of coverage was potentially effective in limiting market failure associated with adverse selection. The impact of mandated benefit statutes was limited due to exemption of self-insured employers under ERISA. It is worth noting that most large self-insured employers (often with populations in several states) typically offered their 
employees health insurance plans that complied or exceeded the terms of most state mandated benefit statutes.

This strategy towards "fixing" difficulties in the insurance market continues today. In 1993 and 1994, debate took place regarding mandated benefits in insurance as proposed under President Clinton's Health Security Act. The inclusion of MH/SA as part of the benefit mandate was especially contentious, primarily because of concerns over the costs of such provisions. The same argument reappeared in 1996 in the form of proposed legislation that would call for parity in benefit design provisions between health benefits and those for MH/SA care. Again, concern over the costs of such mandates and the uncertainty around predicted impacts strictly limited the scope of the legislation that eventually passed (Appropriation Authorization for the Department of Veterans Affairs, 1996). Attenuating selection-related incentives is the main efficiency argument supporting policies to mandate insurance benefits.

\section{Selection and Managed Care: Distorting "Quality"}

As competition among managed care plans becomes the predominant form of market interaction in health care, adverse selection takes a new form which may actually be harder to address in policy, relative to traditional forms of health insurance contracts discussed above. That is, as health insurance moves away from traditional fee-for-service-indemnity arrangements, where enrollees have free choice of providers, and becomes managed care, the mechanisms a health insurance plan uses to effectuate selection change from readily regulated coinsurance, deductibles, limits and exclusions, to more difficult to regulate internal management processes which ration treatment in managed care plans. 
Researchers on the economics and payment and managed care are well aware of the issue. Ellis (in press) labels under provision of care to avoid bad risks as "skimping". Newhouse et al (1997) call it “stinting”. As Miller and Luft (1997) put it:

"Under the simple capitation payments that now exist, providers and plans face strong disincentives to excel in care for the sickest and most expensive patients. Plans that develop a strong reputation for excellence in quality of care for the sickest will attract new high cost enrollees..."

The flip side, of course, is that in response to selection incentives the plan might provide too many of the services used to treat the less seriously ill, in order to attract good risks. A plan, motivated by selection, might provide so many of certain services that enrollees may not benefit in accord to what it costs the plan to provide them (Newhouse et al., 1997). Hence, in the presence of selection-related incentives, capitation and managed care market forces will generate too little care in some area and too much in others.

This set of observations point to the likelihood that competition in the context of managed care health plans will create strong incentives for rationing rules to be based not just on the relative benefits provided by a service given an overall health care budget as was implied by the second best equilibrium among health plans described in section III.B above. Instead, the nature of competition between health plans forces plans to take account of both the direct cost containment impacts of rationing (e.g., setting a shadow price at a given level) as well as indirect effects associated with the types of enrollees that are attracted to a plan under different patterns of rationing across services. The classic asymmetry of information between insurer and enrollees of Rothschild and Stiglitz (1976) along with these market forces may create distortions in rationing rules that result in service competition to attract profitable enrollees. 
We demonstrate this latter point by returning to the model of the planner's problem of setting shadow prices for managed care plans given in equations (1)-(4) above. Consider now profit maximization, and how this condition compares to the condition for efficiency. Profit maximization is used to describe the objectives of the plan. Earlier, in (4), we described the conditions for social efficiency in regard to managed care rationing. If selection were not an issue, a plan seeking to attract enrollees would have incentives to offer efficient insurance (Zeckhauser, 1970). Otherwise, another plan with the efficient combination of premium and rationing would attract the business. With the introduction of selection problems, however, the close relation between the normative (efficient) and positive (profit-maximizing) plan will be disturbed.

Here we characterize the nature of the distortion introduced. We also introduce risk adjustment at this point, since the purpose of risk adjustment is to contend with selection-related incentives. ${ }^{25}$ Define $\mathrm{R}_{\mathrm{t}}$ to be the risk-adjusted payment a plan gets for enrolling a person of type t. ${ }^{26}$ Profits are then:

$$
\pi=\sum_{\mathrm{t}} \mathrm{N}_{\mathrm{t}} \mathrm{R}_{\mathrm{t}}-\sum_{\mathrm{t}} \mathrm{N}_{\mathrm{t}}\left(\sum \mathrm{m}_{\mathrm{st}}\left(\mathrm{q}_{\mathrm{s}}\right)\right)
$$

Recognize that the number of persons of type $t$ joining a plan, $\mathrm{N}_{t}$, is a positive function of the benefits they anticipate, $\mathrm{N}_{\mathrm{t}}\left(\mathrm{B}_{\mathrm{t}}\right)$. Define $\mathrm{C}_{\mathrm{t}}=\sum_{\mathrm{s}} \mathrm{m}_{\mathrm{st}}\left(\mathrm{q}_{\mathrm{s}}\right) . \mathrm{C}_{\mathrm{t}}$ is the cost of a person of type $\mathrm{t}$. The first order condition for profit maximization with respect to $\mathrm{q}_{\mathrm{s}}$ is:

$$
\sum_{\mathrm{t}} \mathrm{N}_{\mathrm{t}}^{\prime} \mathrm{B}_{\mathrm{st}} \mathrm{m}_{\mathrm{st}}^{\prime} \mathrm{R}_{\mathrm{t}}-\sum \mathrm{N}_{\mathrm{t}}^{\prime} \mathrm{B}_{\mathrm{st}} \mathrm{m}_{\mathrm{st}}^{\prime} \mathrm{C}_{\mathrm{t}}-\sum \mathrm{N}_{\mathrm{t}} \mathrm{m}_{\mathrm{st}}^{\prime}=0 \quad \forall \mathrm{s}_{\mathrm{s}}
$$

Rewriting, we have

\footnotetext{
${ }^{25}$ See also the Chapter in this volume on risk adjustment.

${ }^{26}$ This could be regarded as averaged over the characteristics of persons of type $t$.
} 


$$
\sum_{\mathrm{t}} \mathrm{N}^{\prime} \mathrm{B}_{\mathrm{st}} \mathrm{m}_{\mathrm{st}}^{\prime}\left(\mathrm{R}_{\mathrm{t}}-\mathrm{C}_{\mathrm{t}}\right)=\sum_{\mathrm{t}} \mathrm{N}_{\mathrm{t}} \mathrm{m}_{\mathrm{st}}^{\prime}
$$

with the assumption that the demand elasticity for each type of person is the same for any service, this implies:

$$
\frac{\sum \mathrm{N}_{\mathrm{t}} \mathrm{B}_{\mathrm{st}} \frac{\mathrm{N}_{\mathrm{t}}^{\prime}}{\mathrm{N}_{\mathrm{t}}}\left(\mathrm{R}_{\mathrm{t}}-\mathrm{C}_{\mathrm{t}}\right) \mathrm{m}_{\mathrm{st}}}{\mathrm{N}}=1
$$

Comparing conditions (6) and (4) reveals that the efficiency condition is embedded in the profit maximizing condition, allowing us to characterize the distortion caused by selection. The new term is: $\frac{N_{t}^{\prime}}{N_{t}}\left(R_{t}-C_{t}\right) m_{s t}$ in the numerator of (6). The two parts of the term due to the selection distortion have to do with the responsiveness of membership to a change in the anticipated benefits of membership in the plan, ${ }^{27} \frac{\mathrm{N}_{\mathrm{t}}^{\prime}}{\mathrm{N}_{\mathrm{t}}}$, and to the profit and loss consequences of membership of a person of type $t$, and to the level of spending on service $s, m_{s t}$.

Suppose all types are equally responsive to benefits, so $\frac{N_{t}^{\prime}}{N_{t}}$ is the same for all t. Then, the term that will create distortions is the relation of risk adjustment to cost for persons of type $t$ and its correlation with spending for a service. Consider first what happens without risk adjustment. Then, $R_{t}=R$, and a common payment is made for all enrollees. The term $R-C_{t}$ will be smaller for persons of a "high cost" type. If the cross-product of this term with $\mathrm{m}_{\mathrm{st}}$ tends to be large, that is, if people of this high cost type tend to put a high value on service s, then the numerator of (6)

\footnotetext{
${ }^{27}$ For presentational purposes, we disregard here the nature of persons' and plans' expectations about benefits and costs. We treat these as common knowledge. Frank, Glazer, and McGuire (1998) analyze a similar model where the benefit functions are expected benefits by the consumer. Plans set q's on the basis of their expectations of the distribution of consumers' expected benefits in the population. Mental health care is relatively predictable, making mental health possibly more vulnerable to selection incentives.
} 
will be large, and the shadow price for this service will be set "too high" (relative to the social optimum) to discourage membership by this high cost type. If the difference $R_{t}-C_{t}$ is the same for each type $t$, that is, if risk adjustment compensates for type differences in expected cost in a way to equalize $R_{t}-C_{t}$, then risk adjustment will be effectively dealing with the incentive to distort just described. Equation (6) describes a situation where the profit-maximizing plan sets $\mathrm{q}$ "too high" (rationing too tightly) for services that are valued by persons for whom risk adjustment "underpays" and sets q "too low" for services valued by those for whom risk adjustment pays generously. $^{28}$

All services are potential candidates for selection-driven distortions under managed care. This is another way of saying that incentives to under- or over-provide mental health services within a capitated plan must be considered in relation to the incentives to supply other services. Mental health may be one of the services most distorted, but there will be others, and mental health may not be the most in need of economic rescue. Characterizing the incentives and monitoring the actions of managed care plans is a central issue in the economics of health and mental health.

\section{Policy Responses and Managed Care}

Suppose it has been determined that some service, say mental health, needs special protection in a health insurance market with managed care. One implication of our analysis of

\footnotetext{
${ }^{28}$ Frank, Glazer and McGuire (1998) develop this line of argument and propose a distortion index stemming from the selection-related incentives in the context of profit maximizing health plans paid by risk-adjusted capitation. Based on an equation like (6), they show that services that are rationed tightly in managed care are those which are predictable by the individual, and those with a positive correlation with other (predicted) spending. The Frank, Glazer, and McGuire (1998) index is illustrated using Medicaid data for AFDC-eligible adults from the State of Michigan, they calculate the selection-related distortion index for eight major classes of services. Mental health expenditures are relatively predictable, largely because of the high year-to-year correlation. They are not, however, different in their correlation with other costs, at least in this predominantly young, female
} 
managed care is that policies that focus primarily on the nominal insurance benefit will not be sufficient to ameliorate the inefficiencies created by selection-related incentives. Managed care insurance contracts, with their complex rationing devices, are more remote from regulation than traditional fee-for-service-indemnity contracts. Many of the instruments that are used to ration care under managed care are difficult for a regulator to observe and require clinical judgments about individual cases.

An example is the application of the concept of "medical necessity". Most managed health plans cover medically necessary services. Medical necessity and therefore effective coverage depends on a complex set of interactions involving features of the benefit package, the structure of the provider network organized by the health plan, financial incentives facing providers and the administrative mechanisms used to assign patients to specialty care and manage quality assurance. Determination of medical necessity occurs on a case-by-case basis, thereby conferring discretion on those making the decisions such as primary care physicians, plan clinical staff, specialists, and case managers. In a word, the management of care within a health plan has become increasingly non-contractible. The nominal insurance benefit has become one part of a complex contract which rations care and provides protection against the financial risks of treating illness.

For many years, advocates for mental health and substance abuse have sought to achieve "parity" in insurance benefits. The analysis presented above suggests that such efforts, if they are successful, will not be sufficient to guarantee equality in access to services in mental health (Frank and McGuire, 1998). If managed care rationing devices cannot be directly controlled, what options are available to a regulator?

population. Applying the index does reveal that mental health is a service more subject to selection problems, though the results are sensitive to the informational assumptions used. 
Risk adjustment of capitation payments and carve-out arrangements are two responses to selection related incentives. Purchasers of managed care services are making use of each approach to deal with biased selection in the case of mental health and substance abuse. For example, the State of Maryland has chosen to integrate substance abuse services for Medicaid enrollees with all other medical care. Selection related incentives are being addressed by using risk adjustment to adjust capitation rates for differences in enrollee health care risk. In contrast, the State of Arizona carves out (as in Figure 2) all mental health and substance abuse care from its general Medicaid HMOs and contracts separately with one specialized managed behavioral health care organization (MBHO) in each region of the state. A third configuration is being proposed in New York, where mental health is carved out of the Medicaid HMO program. However, multiple MBHOs would be permitted to compete to enroll individuals for their mental health care. Each competing MBHO is slated to be paid a flat capitation fee (Office of Mental Health, State of New York, 1996). How well can risk adjustment and carve-outs be expected to do in countering selection incentives?

\section{D.1. Risk Adjustment}

Managed care plans can engage in various activities designed to select good (profitable) risks from an insurance pool (Cutler and Zeckhauser, 1998). They may prevent or discourage high-cost individuals from joining their plan (sometimes called "dumping") even if this is prohibited under "open enrollment" regulations. They may also distort the services they provide in order to attract the good and deter the bad risks, a perfectly legal activity. Risk adjustment is intended to counter incentives to engage in activities which may lead to inefficient health plan services and unequal access for potential enrollees. 
Risk adjustment of capitation rates makes use of information about the characteristics of individuals to align payments with expected costs. The rationale is that the closer payments track costs, the less services will be the inefficiencies and ones just mentioned. For example, age, sex, welfare status, and county of residence have traditionally been used to adjust Medicare's capitation to HMOs enrolling program beneficiaries. If those over the age of 75 years are found to cost more, premium payments on the behalf of those older beneficiaries are adjusted upward by an estimate of their higher average cost. Most risk adjustment systems rely on demographic factors and clinical information on individuals from past time periods. The clinical information usually consists of diagnoses and procedures arranged in clusters based on clinical judgments regarding the complexity and intensity of past treatment (Ellis et al., 1996; Weiner et al., 1996).

The empirical research used to develop risk adjusters can be viewed in the context of an empirical model of health care spending that relies on pooled time series and cross section data (Newhouse, 1996; Newhouse et al., 1989). Equation (7) is a simple characterization of such a model

$$
S_{i t}=a+X_{i t} B+\mu_{i}+\varepsilon_{i t}
$$

$\mathrm{S}_{\mathrm{it}}$ is spending for individual $\mathrm{i}$ in period $\mathrm{t}, \mathrm{X}_{\mathrm{it}}$ represents a set of characteristics of individuals that are included in the risk adjustment system, $\mu$ is a time invariant individual effect, $\varepsilon_{\mathrm{it}}$ is a possible auto-regressive error with mean zero, and a and B are parameters. Most evaluations of risk adjustment rely on the ability of models such as that given in equation (7) to explain variation in individual spending as measured by an $\mathrm{R}^{2}$ statistic. Newhouse and colleagues (1989) pointed out that a more appropriate standard for judging the ability of a risk adjusted payment system to attenuate selection related incentives is to measure the portion of the "explainable" variance accounted for by the risk adjustment system. Individuals (or plans) can only select a health plan 
(or deter enrollment) based on spending they can predict. If one makes the assumption that individuals know the information contained in a set of $\mathrm{X}$ 's and their past use, the explainable variance consists of variation associated with the Xs, $\mu$, and say auto-correlation in $\varepsilon$ (Newhouse, 1996).

Risk adjustment can be thought of as a tax-subsidy scheme (Diamond, 1994), intended to correct selection-created inefficiencies. Selection problems can take two general forms: individual-based discrimination and plan-wide actions such as service distortions. If an empirical risk adjustment system can set payments at predictable cost person-by-person, both of these selection problems will be eliminated (Van der Ven and Ellis, Handbook). Empirical risk adjusters do not track predictable costs so closely, so the task for economics is to evaluate the efficiency implications of feasible risk adjusters. One way this has been done is by R-squared and related statistical counters(??). These methods quantify how close, in a statistical sense, a given risk adjustment system falls in relation to a first-best system. In a new literature on optimal risk adjustment, weights on risk adjusters (such as age) are variables that are solved for within an explicit market structure and an explicit welfare framework, and this welfare framework can be used to evaluate alternative policies (Glazer and McGuire, 1998; Encinosa, 1998; Shen and Ellis, 1998). This new work suggests that statistical and efficiency criteria do not give identical rankings. In general, the "optimal" risk adjusters from an efficiency standpoint are not regression coefficients that maximize explainable variance in individual-level health care costs.

Classification Systems for Mental Health and Substance Abuse: In the development of risk adjustment systems, little attention has been paid to $\mathrm{MH} / \mathrm{SA}$, partly because initial development of the existing risk adjustment systems proceeded first in the Medicare context, where $\mathrm{MH} / \mathrm{SA}$ is a very small part of total spending. Continued applied research on the systems, 
including use of younger populations, is leading to more attention to $\mathrm{MH} / \mathrm{SA}$. A consistent finding in the research so far, however, is that however past diagnostic information is configured, it has little predictive power in behavioral health (Ettner et al., 1998).

Classification of MH/SA patients has posed a difficult problem for policy makers since the initial introduction of prospective payment policies in the early 1980s. The development of Medicare's Prospective Payment System (PPS) required the federal government to determine whether psychiatric and substance abuse Diagnosis Related Groups (DRGs) constituted an adequate patient classification system. Horgan and Jencks (1987) and Jencks and Goldman (1987) reviewed competing patient classification systems for grouping psychiatric inpatients. Their conclusion, expressing the notion of a low R square in lay language, was: "In general, research has not provided a robust explanation of differences in costs between psychiatric facilities. In particular, research has not developed classification systems that class together inpatient episodes with similar costs or that have substantial differences in costs between classes" (Jencks and Goldman, 1987:S42). The low explanatory power of the DRGs for MH/SA was not the most serious problem. The unexplained variation in cost was systematically related to certain classes of facilities (conditional on the prior reimbursement system). Even after risk adjustment, simulation analyses (summarized in Jencks and Goldman) showed that more specialized psychiatric facilities drew a more costly case mix than general hospitals without specialized facilitates. Thus the initial effect of putting MH/SA into the PPS would have conferred windfall gains (on non-specialized facilities) and losses (on specialized facilities). Responses of facilities to the new system would have modified these loses and gains, but the fundamental unfairness of the PPS in this case, which, we emphasize could only be evaluated with a conception of how the equilibrium would look, could not be avoided (Freiman et al., 1987). 
The inadequacies of inpatient discharge level, risk adjustment raises concerns about the potential of per-person level risk conventional adjustment to adjust capitation rates for mental health care. Other research in health services suggests that the variation in rates of use of MH/SA care might be especially large and difficult to capture with the routinely available risk adjusters. Research on demand for mental health services seldom offers models with explanatory power comparable to those found in general health services. In the RAND Health Insurance Experiment, for example, Keeler et al $(1986,1988)$ were able to group general outpatient medical care into "episodes" and explain the occurrence and extent of these episodes statistically. A similar effort met with much less success in the case of outpatient mental health care.

Two initial evaluations of risk adjusters for MH/SA have been completed using Medicaid and private insurance data sets. Ettner and Notman (1997) evaluated the predictive power of the ACG classification system, a set of diagnostic clusters and age and sex groupings using data on approximately 30,000 Medicaid enrollees in New Hampshire for fiscal years 1993 and 1994. New Hampshire-specific weights for the classification systems were constructed using fiscal year 1993 data to predict 1994 expenditures. The authors evaluated the explanatory power of the classification systems for predicting: 1) total individual health care spending, and 2) individual MH/SA spending. The results reveal several key points. First, none of the classification systems studied explained more than $4 \%$ of variance in total health spending, with the percent of variance explained ranging from $2 \%$ to $4 \%$. Second, in the MH/SA area the maximum explanatory power was $13 \%$ of the variance. Third in the analysis of $\mathrm{MH} / \mathrm{SA}$ spending the results suggest that including age and sex along with a set of variables indicating whether an individual had 1,2 or $3+$ 
separate $\mathrm{MH} / \mathrm{SA}$ disorders indicated in claims during the previous year provided greater explanatory power than any other method. ${ }^{29}$

In the second analysis Ettner et al. (1998) examined risk adjusters within a larger data set of privately insured employees and their dependents for 1992 and 1993. In that study, data from a population of approximately 450,000 enrollees were examined to evaluate several conventional risk adjustment systems. To study the predictive ability of each system for total MH/SA spending, the authors made use of actual health plan choices of employees to assess how well each classification system would account for naturally occurring selection into plans (i.e. selection with no risk adjustment in place). The 1992 patterns of illness were used to classify enrollees and to predict 1993 spending. As in the case of New Hampshire, no classification system displayed strong predictive ability. The results from the analysis of naturally occurring selection across plans for two large employer groups contained in the data illuminated the weaknesses of all the classification systems. ${ }^{30}$ When the payments that would have been made under each classification scheme were compared with payments based on the simple average for all enrollee (across all plan choices) little meaningful improvement was contributed by the risk adjusted payment mechanisms. The results suggest that little of the systematic risk between plans was accounted for by the classification methods examined. Thus, the condition implied by equation (6) to minimize selection is unlikely to be met under any regression-based risk adjustment system.

\footnotetext{
${ }^{29}$ Dunn et al (1995) show that with stratified data and use of ADG, adjusted $\mathrm{R}^{2}$ for total health charges can be as high as 0.20 . This exceeds the explanatory power found in MH/SA. The ADGs are aggregate of ACGs, which include inpatient diagnoses.

${ }^{30}$ The apparent selection across 3 plans may have been quite large. For example, in comparing plans with similar deductibles, differences in annual visit limits of 50, 50 and 25, and similar copayments for outpatient care, per person per year costs ranged from $\$ 6$ to $\$ 105$. Since the cost differences were unlikely to be attributable to differences in limits we interpret cost variation to be largely due to selection.
} 
Risk adjustment policy can be combined with payment system changes. By paying partly on cost as in a mixed system, incentives to select are reduced (Newhouse, 1996). In mental health care, mixed payment systems are in use which resemble the one depicted in Figure 6.

\section{D.2. Behavioral Health Carve-Outs}

Behavioral health carve-outs have become central to payment and delivery of MH/SA services under managed care. Carve-outs are usually regarded as cost control devices. Carving out $\mathrm{MH} / \mathrm{SA}$ from an indemnity plan or in an indemnity/managed care choice plan ensures that all MH/SA care will be managed. (See Figure 1). Carve-outs may also have a role in diminishing selection-related incentives. The economic role of carve-out programs can differ significantly depending on the specific form of the carve-out. For example, the carve-outs shown in Figure 3 are chosen by the health plan and can be viewed as an organizational structure that helps the health plan implement its desired rationing scheme. Viewed in this manner carve-outs which are simple sub-contractors of health plans are not expected to have any impact on selection because consumers continue to choose among integrated health plans where the implementation of rationing rules across services can affect enrollment patterns. The incentives to ration MH/SA care to the organization are present with and without a carve-out contract.

In contrast, the type of carve-out program depicted in Figure 2 separates MH/SA services from overall health care and as such removes it as a dimension of competition among health plans for enrollees. This can have potentially large impacts on the incentive to provide services. Carving-out a service, $\mathrm{MH} / \mathrm{SA}$ in this case, isolates $\mathrm{MH} / \mathrm{SA}$ from selection-related incentives. Rationing will be determined by the contract between the payer and the specialty MBHO. It is also important to note that the rationing for any one service depends on all the other service demands. Thus, carving-out any one service will affect the degree of rationing for all others. 
Carve-out programs have other pros and cons that must be considered along with the potential welfare gains related to selection. One controversial question relates to whether $\mathrm{MH} / \mathrm{SA}$ care is more effectively delivered in a fashion that is integrated with medical care via a primary care physician. In theory, "integrated" care is better than "fragmented" care. In practice, a separate mental health system has some advantages. Primary care physicians tend to overlook mental illness in their patients (Jencks, 1985; Morlock, 1989). When mental illnesses are recognized primary care physicians often fail to provide appropriate treatment (Shapiro et al., 1987, Wells et al., 1996).

Carve-out programs add administrative costs. Estimates of the additional administrative costs associated with carve-out arrangements range from $8 \%$ to as much as $20 \%$ of $\mathrm{MH} / \mathrm{SA}$ benefit costs. Finally, new boundaries between payers' responsibility creates opportunities for cost-shifting and strategic behavior. Anecdotal evidence suggests that carve-out plans are especially prone to adopt pharmacotherapeutic strategies because the drug benefit represents an "off budget" set of treatments. Brisson et al. (1998) finds a higher propensity for individuals with histories of substance abuse treatment to be hospitalized in a general medical setting following introduction of a carve-out plan.

\section{The Public Mental Health and Substance Abuse Treatment System}

A unique feature of mental health care delivery in most western nations is the large role assigned to public hospitals and clinics for the care of individuals with mental and addictive disorders. Direct public services for the most seriously ill persons is a common feature of health systems that may otherwise be organized to provide and pay for other health care with a range of approaches (Hollingsworth, 1992). The public mental health systems in the United States, 
Germany, Canada, Great Britain and France are quite similar, despite vast differences in their general approaches to health care financing. Each of these nations assigns responsibility for mental health care to sub-national government (e.g. states in the U.S., länder in Germany, provinces in Canada and local authorities in the United Kingdom) and tends to rely on local tax funding more than either central government or premium-based funding. The role of local government-provided mental health care predates the development of either public or private insurance arrangements and tends to emphasize providing care to the poor and disabled. These public mental health systems have been the source of public dissatisfaction with respect to the quality of care and horizontal equity (Mangen and Rao, 1985; Mehnte, 1989). Yet they continue to play central roles in the care of severe mental and addictive illnesses.

There are three main factors that explain the commonality. First, the technology of treating severe mental disorders calls for different organizational and financial arrangements from other medical conditions. Second, public mental health systems predate modern insurance arrangements, and these established systems of public provision may have inhibited other forms of financing for mental health and substance abuse. Third, the externalities created by mental illnesses means that provision of mental health care has a public safety component and therefore the state has a greater interest in assuming more direct control over the delivery of certain forms of mental health care to fulfill its obligation of public protection.

\section{A. The Technology of Treatment for the Severely Mentally Ill}

The acute health care delivery system is ill-equipped to deal with the array of problems associated with severe mental disorders. Mechanic (1989) describes the complexity of services required for treatment of individuals with severe mental disorders this way: 
"Effective community care for the most seriously disabled patients requires performance of many of the same functions as the mental hospital, ranging from assuring appropriate shelter to managing serious medical and psychiatric problems. To do so in the community context requires some influence over areas of responsibility involving different sectors (housing, medical care, social services, welfare) .... (p. 492)

This characterization suggests important differences in the technology required for treating the sickest and mostly costly people with mental illnesses from those with most medical conditions. The observation that medical care delivery systems have difficulty accommodating individuals with chronic diseases has been widely acknowledged in other contexts (Moon, 1996; Wallack and Levine, 1996). It appears that this point applies with special force in the case of severe mental disorders.

Treatment programs aimed at people with severe mental illnesses must concern themselves with the acute care of the symptoms of illness, as does the rest of medicine. In addition, however, mental health care must address the housing, income support, rehabilitation, social contacts, and social control of the affected individuals. The nature of severe mental illnesses and their treatment requires that mental health providers coordinate these services. Many of the most successful innovations in the treatment of severe mental disorders involve new ways of organizing and coordinating the various elements of care for individuals with severe mental disorders (Stein and Test, 1980; Dill and Rochefort, 1989; Schwartz, Goldman and Churgin, 1982, Taube, Morlock, Burns and Santos, 1990). The health systems in the U.S., Germany, Britain and Canada all confine responsibility of the medical care system for mental health services and treatments to those that roughly correspond to acute care medical treatments. Such actions are consistent with recognition of a different technology of treatment that may call for a different set of institutions. 
In European contexts, the organizational response to differences in technology for treating people with severe mental disorders in great measure reflects the political choices of planners or the results of political bargaining between different levels of government. In the U.S. context, the organizational response to the needs of persons with serious mental illness represents a different set of forces involving market failure, perhaps due to adverse selection and externalities (discussed below), and the economics of a federalist system.

\section{B. Fiscal Federalism and Public Mental Health Care}

In assessing the lessons from the history of mental health policy, Grob (1994) points to the evolving nature of fiscal federalism as a central force in shaping the role of government in mental health care delivery. He goes so far as to assert that for some payers, including states, cost shifting has been as important in designing policies as the impetus to construct a "rational" system. "Deinstitutionalizing" the mentally ill refers to shrinking or closing state hospitals, and transferring the care of previously hospitalized patients to a diverse set of care providers. While a rationale for deinstitutionalization can be made on the basis of single system cost-effectiveness, cost-shifting was also a motive. State government in the U.S. paid the costs in state hospitals, and only a share of the costs of care given by alternative providers, courtesy of the federal Medicaid program.

Since states (and other regional governments outside the U.S.) make the majority of spending decisions about public funds for care of mental disorders, the literature has naturally directed attention towards state choices regarding mental health policy. A simple starting point for analyses of state mental health policy is to view state policy decisions as being the result of choices by a social planner seeking to coordinate mental health services for the poor. State policy makers have two major instruments: direct state spending on services, and the insurance-like 
Medicaid program. Michael (1980) and Frank (1985) regard the "state" as a single decisionmaker with an objective function containing: welfare for the poor and state budget costs. The choices of the state planner are constrained by factors such as the income in the state, the size of the public mental hospital system, the availability of alternatives to state funded providers (e.g. nursing homes), federal rules governing Medicaid especially the federal matching rate on spending, ${ }^{31}$ and the amount of private insurance coverage in a state. Direct state spending on mental health care will be reduced, according to this approach, by generous federal matching provisions, $^{32}$ the availability of care in settings funded by Medicaid (nursing homes), and expansion of private insurance coverage for mental health care. These all point to rational cost shifting responses to exogenous changes in regulation and market structure.

Although few formal analyses of mental health financing for countries other than the U.S. have appeared in the literature, similar observations have been made about the relation of central government financing to local funds. For example, Britain has experimented with central government matching grants to local authorities (Knapp, 1990; Yellowlees, 1990). In general, these schemes have not resulted in the desired effort by localities. In Germany, the sickness funds have resisted expanding benefits to include long-term care for mental disorders due to concerns that costs would be shifted from the lander to the sickness funds (Cooper and Bauer, 1987).

Existing empirical evidence from the U.S. is broadly consistent with the single decisionmaker model predictions. For example, Frank (1985) using a cross section of states for the year 1976 found that the state share of the Medicaid program was positively related to per capita state

\footnotetext{
${ }^{31}$ The Medicaid program in the U.S. matches state spending according to a formula based on per capita income. The federal government constrains minimum participation to 50\% and maximum matching rates are about $78 \%$. This formula favors high-income states.

${ }^{32}$ It is possible that the state's elasticity of demand would be high enough to reverse this result, but this is very unlikely.
} 
spending for direct mental health services. The size of state mental hospital systems (relative to population size) was estimated to have a large positive impact on spending, while the presence of a mandated mental health care insurance statute (creating another destination for cost-shifting) reduced state mental health spending. Michael (1980) found that the availability of nursing home services led to reduced use of state mental hospitals. He also shows that the number of mental hospitals per state senatorial district was estimated to have a positive and significant impact on the use of public mental hospitals. Gronfein (1985) found that the introduction of Medicaid, and its opportunity for shifting mental health costs from state budgets was the most important factor determining the rate of deinstitutionaliztion in states. The Medicaid impact dominated the effects of innovation in drug treatment and the creation of community mental health centers. During the period 1955 to 1965 , the populations of public mental hospitals were reduced by about $1.5 \%$ a year. Following the implementation of Medicaid the rate of population reduction increased to $6 \%$ a year.

The prominence of cost shifting in state mental health policy explains tensions between federal (or central) governments and local governments in the United States and other western nations in mental health policy. For example, when the Medicaid and Medicare programs were implemented in the United States, Congress included provisions which prohibited Medicaid reimbursement for care provided in an "Institution for Mental Disease" (IMD) and limited Medicare hospital payments to 190 days over an individual's lifetime. These rules were aimed at preventing states from shifting the costs of state mental hospitals onto the federal government's budget (which turned out to be partially and temporarily successful). Thus, once the federal government appreciates the responses it will get in a cost shifting game with the states, the result 
will be a division of labor that may leave states with their historical responsibility for public mental hospitals that care for the most impaired and difficult indigent people with mental disorders.

Cost shifting has also been reported in Canada. Following adoption of the National Health Insurance plan in 1968, Nova Scotia and other provinces attempted to reorganize mental health services in order to capture health insurance payments for services which were previously the responsibility of the provincial government (Rochefort, 1993). The National Health Insurance plan guarded against cost shifting by (1) strictly limiting the range of providers who could be reimbursed for supplying mental health care (MDs only), and (2) limiting the scope of services to acute care treatment, thereby excluding day treatment and rehabilitation services.

While single decision-maker models are adequate to explain cost shifting behavior between federal and state (regional) government, this approach may not offer a fully satisfactory explanation for observed patterns of mental health policy. Within a state, agencies (Medicaid, mental health, substance abuse) may behave as independent (and possibly competing) organizations. Casual observations have noted policies which shift responsibility for care of individuals with mental disorders from state mental health agencies to social welfare agencies, school systems and criminal justice programs. Such observations suggest the limits of characterizing state government behavior in terms of a single planner that coordinates policy (Rochefort, 1993; Mangen and Rao, 1985; Cooper and Bauer, 1987). One way to investigate the empirical importance of a state's organizational choices is to see if different state's approaches to dividing up administrative responsibility for Medicaid, mental health, substance abuse, and related services affect the level of state spending on those services. Using a time-series of the fifty states in the United States, Jacobsen, Notman, and McGuire (1996) found that organizational changes, such as putting responsibility for substance-abuse services in a mental health department had, 
predictable, but small, effects on levels of spending. If intrastate division of labor among agencies matters for state fiscal outcomes, the single decision-maker model is contradicted.

A natural way to regard intergovernmental relations is as a sequential game consisting of the federal government, state government, local government and participants in private markets (Frank and McGuire, 1996). The federal government makes policy given the historical role of the states which in turn sets the stage for state policy action. The state and federal policies determine the outlines of the market where private parties buy and sell insurance against the consequences of mental and addictive illnesses.

Within this framework, the federal government sets rules for public insurance programs (Medicaid) that seek to limit the shifting of the costs of state mental hospitals from state to federal budgets. Marmor and Gill (1989) propose a political model along these lines that applies to the U.S. and Britain. The IMD rule associated with the U.S. Medicaid program, noted above, is one example of a policy adopted to reduce cost shifting by states. States in turn responded to matching provisions under Medicaid by orienting program design towards Medicaid. For example, state governments shifted large numbers of elderly residents in state mental hospitals to nursing homes following the introduction of Medicaid in the late 1960s. This meant that the costs of treating one segment of the elderly population were moved entirely off budget for the state mental health agency. State governments retained some financial responsibility via matching provisions, of roughly $30 \%$ to $50 \%$, assigned to the state under the Medicaid program.

States also set general rules within which individual agencies and local governments operate. Within state governments, funding for mental health care and substance abuse treatment is administered and often supplied separately. Nevertheless, there is considerable co-occurrence of these classes of disorders. Current clinical thought suggests that organizational and payment 
arrangements stand in the way of effective treatment for this class of expensive and disabling conditions. Policy regarding utilization of state mental hospitals offers an example of the response by local mental health systems to of state payment rules. For many years state mental health agencies provided public mental hospital services to local public mental health programs "free of charge" (Frank and Gaynor, 1995). One result was a tendency of local programs to "overuse" state mental hospitals. This set of institutional arrangements has been pointed to as leading to distortions in spending towards state mental hospitals and to inefficiently low levels of effort aimed at treating people with severe mental illness in community programs (McGuire and Riordan, 1995).

Private insurance markets offer insurance designs in the context of a public mental health system that will provide hospital and outpatient care for mentally ill individuals without insurance coverage. Approximately 55\% of individuals admitted to public psychiatric hospitals in 1994 had no insurance coverage. In addition, a significant number of people in state hospitals with coverage had exhausted their mental health benefit. The presence of a public mental health system along with market forces associated with selection incentives discussed above serve to undermine the provision of private insurance for mental health and substance abuse care. The availability of publicly funded and provided mental health care allows employers to strictly limit insurance coverage for mental health care while at the same time giving their employees recourse should a catastrophic mental illness strike. As noted earlier, mandated mental health insurance statutes represent a policy response by states to market failures stemming from adverse selection. Mandates also represent a means of shifting costs from state government budgets to private employers (Frisman, McGuire and Rosenbach, 1985). Mental health mandates have been politically contentious in state legislature and have been limited in their effect by federal policy. 
The federal Employment Retirement Income Security Act (ERISA) allows self-insured firms to be exempt from state laws which govern the business of insurance. During the 1980s and 1990s an increasing number of mid and large size firms have chosen to become self-insured. The consequences are that in most states only a modest portion of the population is subject to mandated benefit statutes. Thus, federal policy has limited the ability of states to 1) address market failure in insurance and 2) shift costs onto private employers.

Mental health policy can be viewed as a cascading cost shifting game. Each of the players across levels and within levels of the game makes choices subject to rules set at a higher level. Players are presumed to be aware of the behavior of other players at the same level and below and develop policies accordingly. These ideas appear also to apply in nations with federal types of systems in mental health, including Britain, Germany, and Canada (Yellowlees, 1990; Marmor and Gill, 1989).

\section{B. Externalities and Public Mental Health Care}

Prior to the 1820 s, mental problems were not so clearly part of the medical domain. Care for "lunatics" or "distracted " persons was provided through a variety of informal mechanisms (Grob, 1994). Poor houses and almshouses were settings for the support of people with disabling mental problems. During the first part of the $19^{\text {th }}$ century a new institution, the asylum, became the focal point for treatment of more clearly recognized mental illnesses. Initially these institutions were the shared responsibility of state and local governments. State government in the 1820 s and 1830 s typically provided capital financing for asylums and localities paid for operating expenses. Initially, the priority populations for treatment in asylums were individuals viewed as "dangerously insane" (Grob, 1973). The requirement that local government pay for costs of treating mentally ill people in asylums created an incentive for localities to continue 
housing the mentally ill in almshouses which had very low per diem costs. Aware of the problems created by divided responsibility for asylums, states began to take over all financial and operational responsibility for asylums. As financial responsibility shifted to state governments, localities developed new enthusiasm for the use of asylums to treat the mentally ill. Not only did localities transfer responsibility to state asylums for individuals that were "chronically" mentally ill, they also redefined senility as a psychiatric condition and shifted responsibility and the costs of caring for the senile elderly to the state. The state has had the paramount role in mental health policy ever since.

Thus from early in the $19^{\text {th }}$ century to the present the state mental hospital system (and later state mental health systems) has played two roles. First, it has served as an institution for involuntary treatment and confinement of individuals who were viewed as dangerous due to a mental disorders. Second, it has served as a safety net institution for housing and care of other disabled and vulnerable populations (initially the senile elderly, later chronic brain damaged alcoholics). Two roles of the state have been used to justify the presence and persistence of a public mental health system that supplies involuntary treatment (Rubin, 1978). These are the parens patriae doctrine and the police power of the state. The parens patriae doctrine claims that when an individual is mentally incapable of taking care of him or herself, the state may serve as an agent of the individual and institutionalize the individual in order to care adequately for them. The police power of the state justifies institutionalization of individuals who are a danger to themselves or others in order to protect the individual or society at large. In the latter case the state can choose between separating an individual from society and offering treatment via the mental health system or through incarceration in the criminal justice system. 
The presence of external effects provides an efficiency underpinning to both justifications for assigning the state a role in involuntary commitment for mental health care. The parens patriae doctrine substitutes judgments of the state for individual choice based on the notion that there is a collective interest in seeing that individuals who are so impaired by mental disorders receive sufficient care so as to survive and possibly improve their ability to function or recover. This collective interest is a consumption externality, the polity benefiting from consumption of mental health care by those too impaired to make such choices on their own. The police power rationale also involves an externality. Protecting affected individuals intent on harming themselves or protecting the general public from individuals whose mental disorders make them dangerous to others through treatment and confinement also confers external benefits. Publicly funded mental hospitals that care for these individuals generate some non-excludable benefits and therefore have a public good feature.

All U.S. states have laws and regulations that govern the process by which individuals can be involuntarily committed to mental institutions. Since the early 1970s there has also been judicially imposed regulation concerning the conditions of the institutions to which these individuals are committed. Over the past 30 years there has been considerable flux in public policy regarding involuntarily commitment to mental hospitals (Rubin, 1978). Since the early 1970s state psychiatric hospitals have been required to provide active treatment and to have physical facilities and staffs that are consistent with what the courts have viewed as the ability to provide active treatment.

Empirical analyses have shown that commitment laws and regulations, as well as courtdictated facility and staffing guidelines, have had a significant impact on the size of the populations served in public mental hospitals as well as the budgets of those institutions. 
Lambrinos and Rubin (1981) used a simultaneous equations model to estimate the impact of commitment laws and regulations on average daily census and spending on public mental hospitals with data from 1974 and 1975. Their results showed that states that institute mechanisms to protect patient rights such as appointment of an attorney and requiring a formal hearing tend to reduce use of mental institutions. States that clearly define "risk" and disability in their commitment statutes also tend to have lower rates of institutionalization. Rubin (1980) and Lambrinos and Rubin (1981) offer evidence suggesting that the regulations setting out standards for staffing and the physical plants of state hospitals have increased spending on public mental health care.

The state responsibility for public protection and the care of those who cannot fend for themselves is a long-established basis for the public mental hospital, a role predating the development of either public or private insurance mechanisms. Most states continue to have laws in place that tend to favor society's interests (externalities) over individual liberties of the mentally ill. This in part explains the persistence of the state role in provision of mental health care. Litigation and court decisions during the 1970s have forced states to provide treatment in public mental institutions which, in turn, increased spending on those institutions in the 1970s and 1980s. ${ }^{33}$ At the same time the division of labor has shifted whereby private organizations have increasingly served individuals with insurance (public and private) who are involuntarily committed. State mental hospitals have become facilities that serve the most impaired, dangerous, and indigent people with mental illness. Privatization of production in this area of service has been quite limited.

\footnotetext{
${ }^{33}$ For an overview of the troubling history of the state mental hospital in the United States see Grob $(1973,1994)$.
} 


\section{Conclusions}

Economic analyses of the cost of illness and other assessments of the global burden of disease testify to the disabling effect of mental disorders. Mental illnesses often persist, and can be accompanied by a range of social pathologies, generating public misunderstanding and fear. Public safety is therefore viewed as a key product of the mental health care system, one factor in explaining the major role assigned to government in the financing and delivery of mental health services relative to what is found in general medical care. There is an unresolved tension between the insurance-medical care delivery aspects of mental health care and the public safety role. For most of this century the public safety role featuring direct government provision appears to have dominated the organization and financing of this system. Nevertheless, over the past thirty years, private institutions and markets have ascended to important positions in the provision of mental health services. Markets for health insurance and health services have developed against a background of large publicly funded and managed mental health system, though downsizing has been one key force affecting the development of private insurance markets in the U.S. and the design and implementation of public insurance in the U.S., Britain and Canada among other nations.

Concerns about insurance arrangements in mental health relative to general medical care have dominated policy debates in the mental health arena during the 1980s and 1990s. Here the traditional factors which threaten the efficient functioning of insurance markets, adverse selection and moral hazard, are important for understanding the performance of the market with regard to mental health care. Mental health advocates are troubled by the "special treatment" of the mentally ill in the structure of private insurance. Advocates have tended to understand the special 
treatment as discrimination rather than as a response to economic fundamentals. Payers have been deeply troubled by the cost control problems associated with coverage of mental health care under indemnity-fee for service arrangements.

In economic terms, the behavior of providers and consumers in the market for mental health services reflects the characteristics of mental health disorders and their treatments. Adverse selection and moral hazard appear to hit mental health markets with special force. In some of the first economic research on mental health, the demand response was found to be high. The persistence of many mental disorders and the fact that people most likely to suffer from mental disorders are most likely to choose health plans with generous mental coverage suggests strong incentives for plans to limit mental health coverage. Sorting out the roles of moral hazard and selection in explaining observed market outcomes, and in terms of the implications for optimal policy, has been an ongoing theme in research in the economics of mental health.

The basis for the institutions governing coverage for mental health care have been dramatically altered by managed care, which changes the terms of Zeckhauser's dilemma, wherein coverage should balance losses from risk and moral hazard. Mental health services are now rationed by means other than demand-side prices. Even though little is known about internal rationing methods used within managed care organizations, the ability to control costs in this way means that the main efficiency argument against parity in mental health coverage is potentially weakened under managed care. At the same time, parity in demand-side cost sharing delivers less because expanded nominal coverage is no longer a guarantee of access. Demand-side cost sharing may no longer be the binding constraint on use.

Managed care has also continued to treat mental health differently than other illnesses, the most important example being the emergence of behavioral health carve-out programs. Are these 
institutions a fiscal discrimination against the mentally ill, or a response to market failure? Economic research understands these institutions in terms of key functions that they serve. The first relates to economies of specialization and control of moral hazard, while a second involves attenuation of selection related incentives common in competitive insurance markets. Payer carve-outs may increase market efficiency by removing mental health from competition for "good risks" among health plans.

As the focus of government policy towards mental health has shifted towards treatment and away from public safety, maintenance of large publicly supported institutions has been harder to justify. The public mental hospital is increasingly being consigned to care for involuntarily committed individuals and the severely impaired, narrowing its public safety function. The emergence of private providers of managed behavioral health care that will assume some risk, has proved to be an attractive alternative to a number of states. The result is a shifting of functions for many state governments from payer (via grants) and provider to payer (via contracts) and regulator. A key dilemma facing the states is that while insurance markets continue to be subject to failures stemming from selection related incentives, state Medicaid programs and the related federal disability programs are becoming increasingly restricted. States remain nevertheless responsible for the indigent mentally ill, yet they are reducing the infrastructure available to attend to the mental health needs of these vulnerable populations. How states will choose to address their traditional role as provider of last resort in the context of the new private market for mental health care is unclear. What is clear is that in the past fifty years resource allocation in mental health in dealing with state government has moved steadily out of the realm of public administration and into the domain of economics and mental health. 


\section{Figure 1}

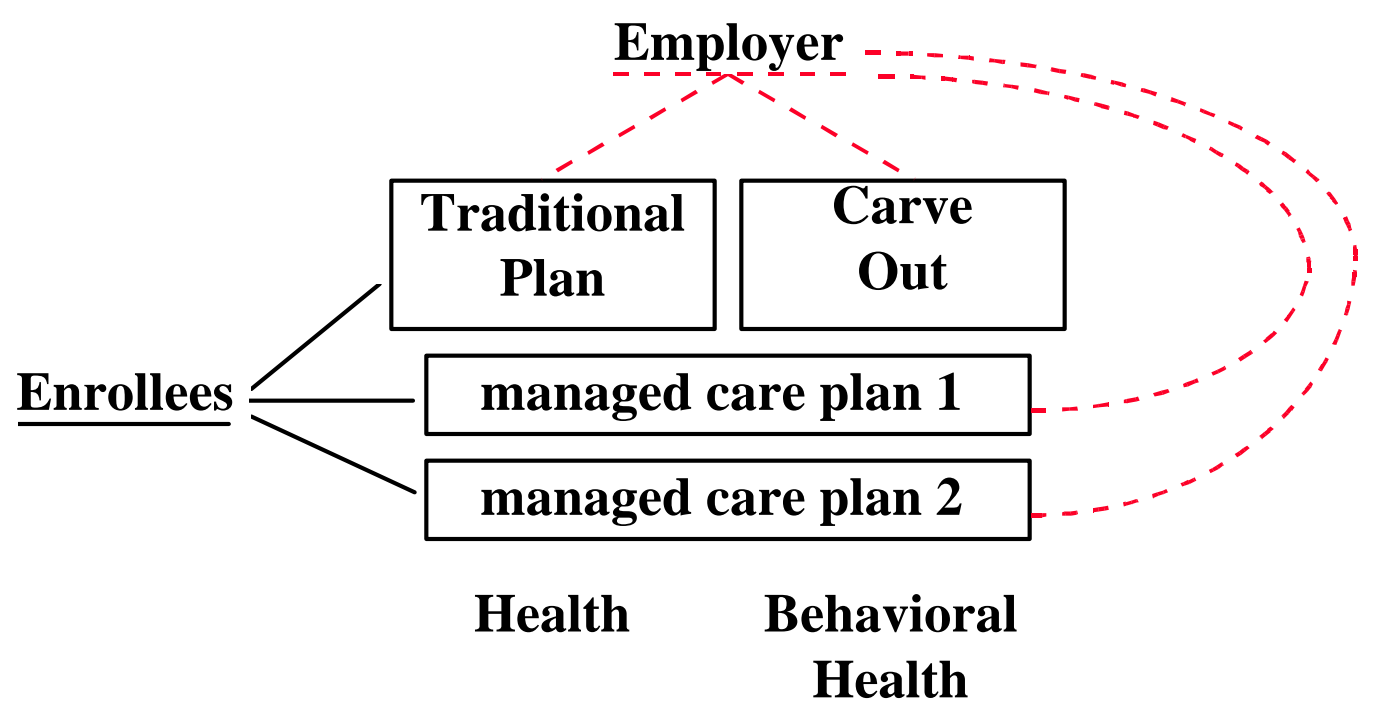




\section{FIGURE 2}

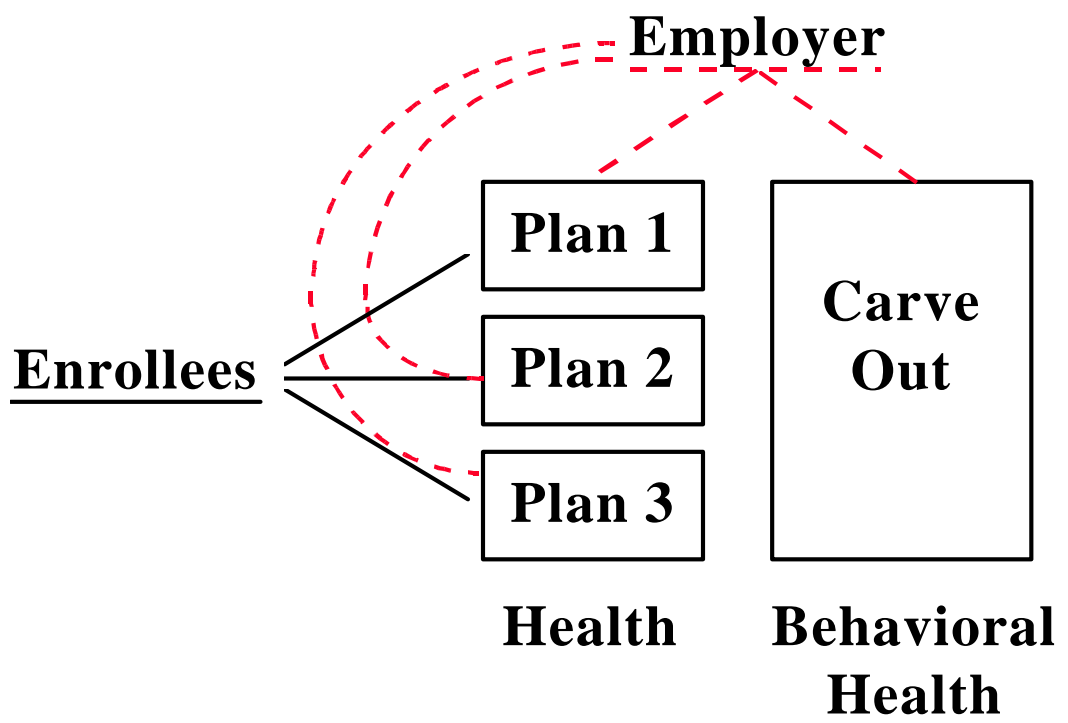




\section{Figure 3}

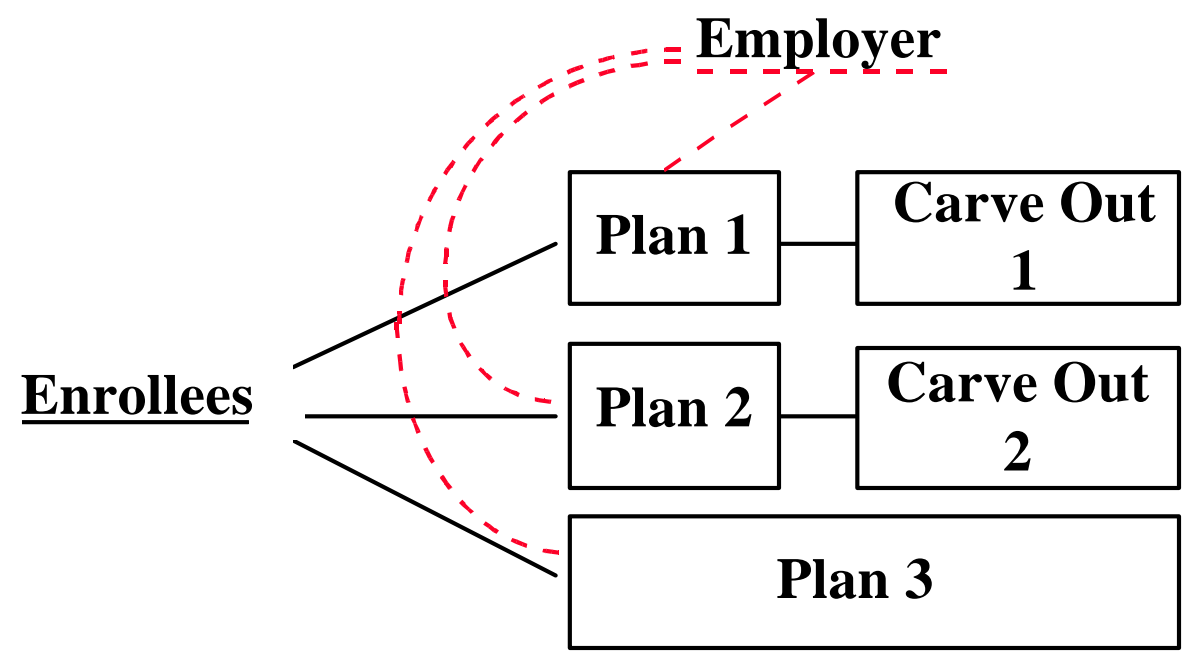

\section{Health Behavioral Health}




\section{FigURE 4}

\section{Non-Linear Price Schedules ANd Demand for MH/SA CaRe}

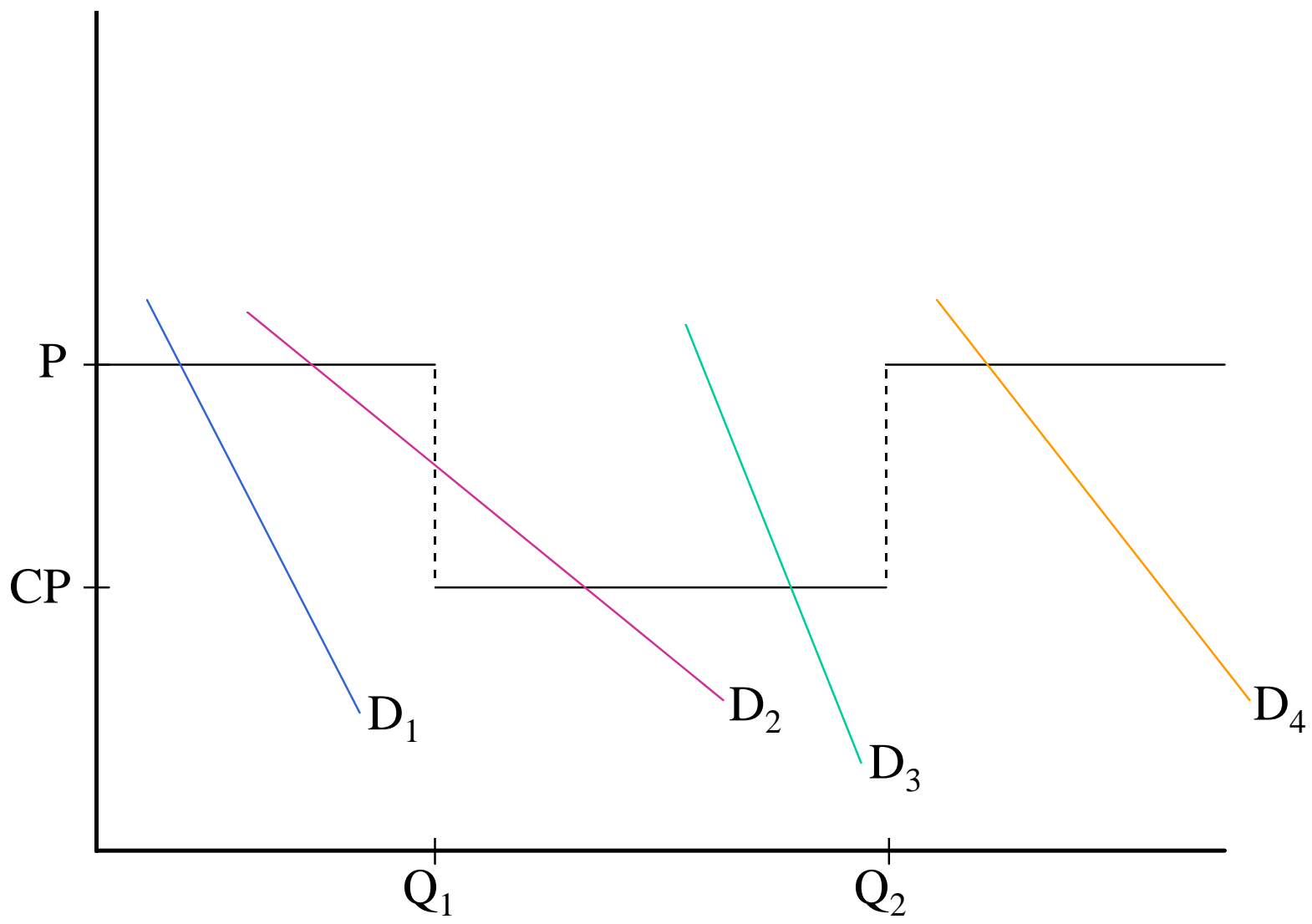

Source: Frank, RG and Manning, WG. Economics and Mental Health. The Johns Hopkins University Press: Baltimore, 1992. 


\section{FIGURE 5}

\section{Managed Care Rationing by Shadow Prices}

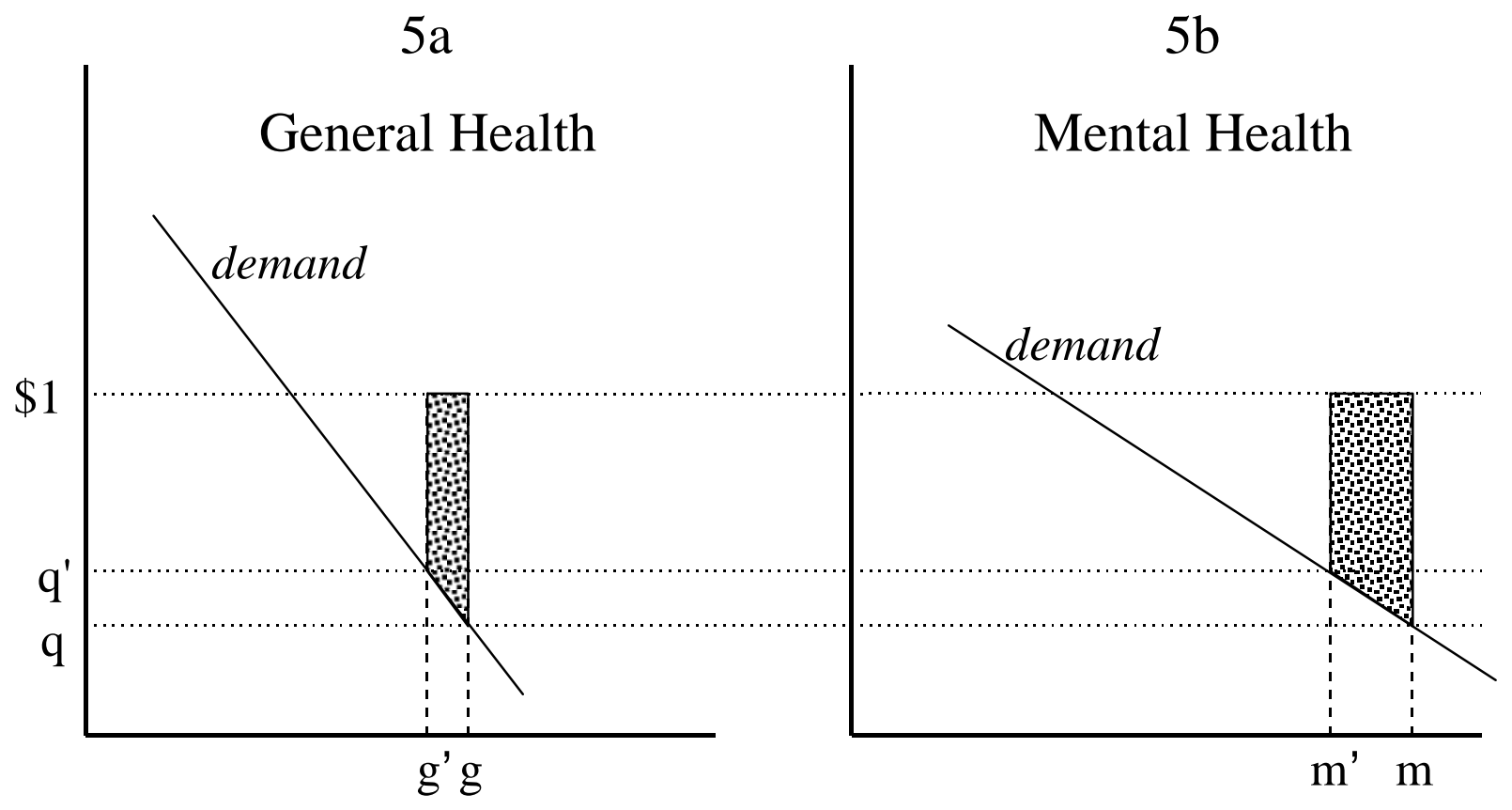




\section{FIGURE 6}

\section{PAyment Systems for MANAged CARE}

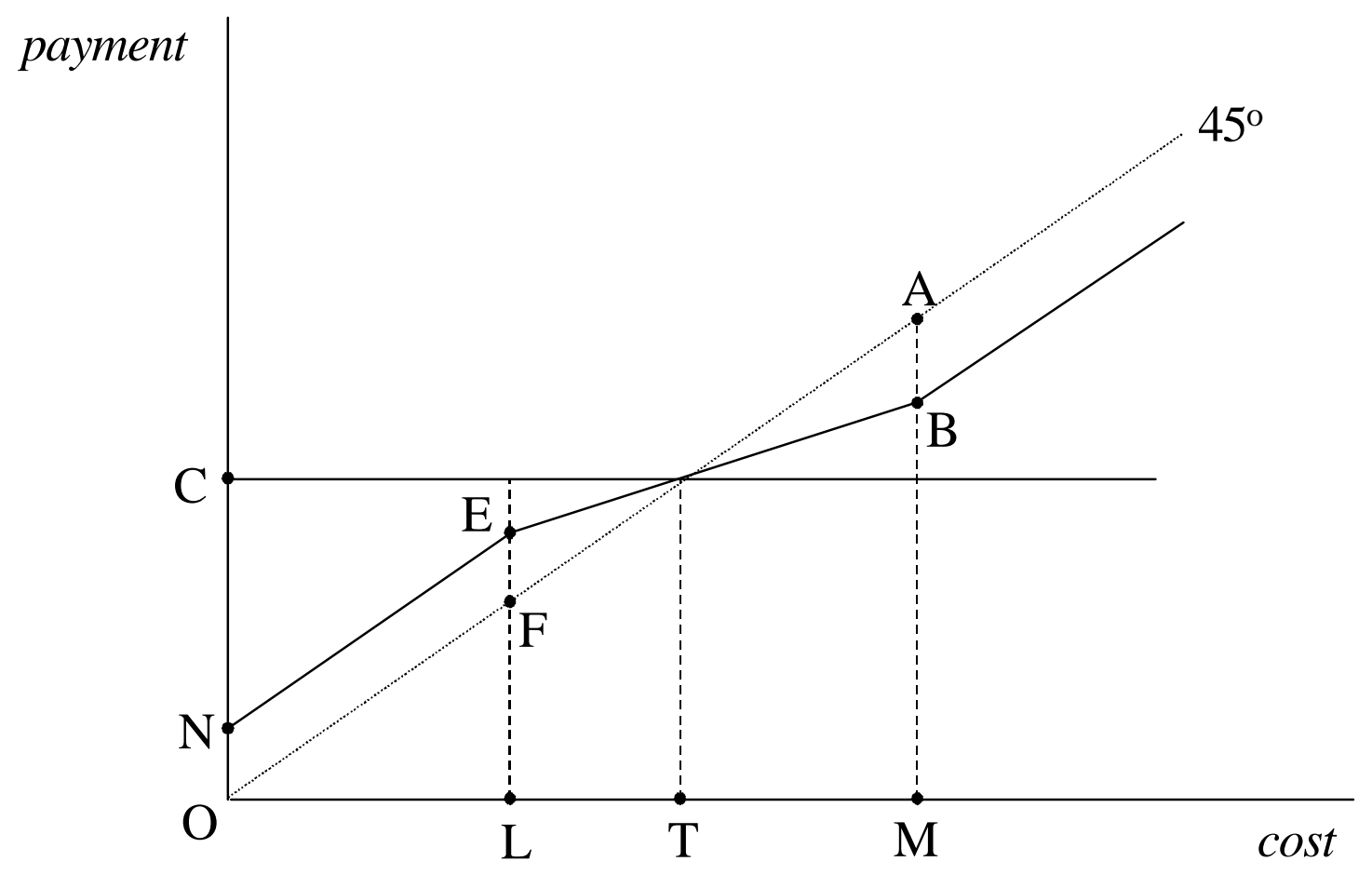




\section{TABLE 1}

Mental Health and Substance Abuse SPending by Source OF Payment, U.S., 1996

\begin{tabular}{lcc}
\hline \hline Payer & MH/SA \%* & All Health \%* \\
\cline { 2 - 3 } Private Insurance & 25.8 & 31.0 \\
Private Out-of-Pocket & 15.1 & 18.1 \\
Medicare & 14.0 & 21.0 \\
Medicaid & 18.8 & 14.8 \\
Other Federal & 3.9 & 4.3 \\
Other State/Local & 19.4 & 7.2 \\
Other Private & 2.7 & 3.3 \\
Total & 100 & 100 \\
\hline \hline
\end{tabular}

* Percentages may not sum due to rounding.

Source: McKusick et al., 1998 


\section{TABLE 2 \\ Spending on Specialty Care Organizations, U.S. \\ (NOMinal DOLLARS)}

\begin{tabular}{|c|c|c|c|}
\hline & & 1969 & 1994 \\
\hline State Mental Hospitals & & $\$ 1,814$ million & $\$ 7,824$ million \\
\hline General Hospital Psychiatric Units & & 298 & 5,344 \\
\hline Private Psychiatric Hospitals & & 450 & 6,468 \\
\hline VA Medical Centers & & 122 & 1,386 \\
\hline Residential Treatment Centers & & 186 & 2,360 \\
\hline Free Standing Clinics & & 202 & 6,046 \\
\hline \multirow[t]{2}{*}{ Community Based Treatment Programs } & & 220 & 3,706 \\
\hline & Total & $\$ 3,293$ million & $\$ 33,136$ million \\
\hline
\end{tabular}

Source: Mental Health, United States, 1998. 


\section{TABLE 3 \\ RESEARCH ON DEMAND RESPONSE}

\begin{tabular}{llcc}
\hline \hline \multicolumn{1}{c}{ Study } & Type of Elasticity & MH/SA Estimate & General Health Estimate \\
\hline McGuire (1981) & Point & -1.00 & \\
Taube et al. (1986) & Point (level of use) & -0.54 & -0.13 \\
Horgan (1986) & Point (level of use) & -0.44 & -0.16 \\
Ellis and McGuire (1986) & Point (level of use) & -0.37 & \\
Manning et al. (1988) & Arc & -0.80 & -0.30 \\
\hline \hline
\end{tabular}

Source: McGuire (1989) and authors' calculations 


\section{TABLE 4 \\ CARVE-OUT IMPACTS}

\begin{tabular}{cccc}
\hline \hline Case & $\begin{array}{c}\text { Risk } \\
\text { Arrangement }\end{array}$ & Impact & Studies \\
\hline Mass GIC & RS & $\begin{array}{c}\text { Pre-post Outpatient Spending } \\
(-25 \% \rightarrow-16 \%)\end{array}$ & $\begin{array}{c}\text { Ma and McGuire (1998) } \\
\text { Huskamp (1997) }\end{array}$ \\
& & $\begin{array}{c}\text { Total Spending } \\
(-32 \%)\end{array}$ & \\
& & & \\
Mass Medicaid & RS & $\begin{array}{c}\text { Pre-post Spending } \\
(-26 \% \rightarrow-22 \%)\end{array}$ & Frank et al. (1996) \\
& & Frank and McGuire (1997) \\
& & Pre-post Spending & Christianson (1995) \\
Cap & $(-17 \%)$ & \\
Utah Medicaid & & & Goldman et al. (1998) \\
Pacific Bell & ASO & Pre-post Spending & \\
$1988-1995$ & & $(-43 \%)$ & \\
& & & \\
\hline \hline
\end{tabular}

ASO $=$ Administrative Service Only

$\mathrm{RS}=$ Risk Sharing

Cap $=$ Capitation 


\section{REFERENCES}

American Psychiatric Association (1995), Diagnostic and Statistical Manual IV, APA Press: Washington, DC.

Appropriation Authorization for the Department of Veterans Affairs, (1996).

Arrow, K.J. (1963), "Uncertainty and the Welfare Economics of Medical Care," American Economic Review, 53: 941-969.

Assistant Secretary for Planning and Evaluation (ASPE), (1994). Substance Abuse Among Women and Parents, USDHHS: Washington, DC.

Barr, N. (1992), "Economic Theory and the Welfare State: A Survey and Interpretation," Journal of Economic Literature, 30(2): 741-763.

Bartel, A. and Taubman, P. (1986), "Some Economic and Demographic Consequences of Mental Illness," Journal of Labor Economics, 4(2): 243-56.

Baumgardner, J. (1991), "The Interaction between Forms of Insurance Contract and Types of Technical Change in Medical Care," RAND Journal of Health Economics, 22(1): 36-53.

Beinecke, R.H., Shepard, D.S., Goodman, M., and Rivera, M. (1997), "Assessment of the Massachusetts Managed Behavioral Health Program: Year Three," Administration and Policy in Mental Health, 24(3): 191-204.

Berndt, E.R., Cockburn, I., and Griliches, Z. (1996), "Pharmaceutical Innovations and Market Dynamics: Tracking Effects on Price Indexes for Antidepressant Drugs," Brookings Papers on Economic Activity: Microeconomics 1996, Brookings Institute, Inc., 133-188.

Berndt, E.R., Frank, R.G., and McGuire, T.G. (1997). "Alternate Insurance Arrangements and the Treatment of Depression: What are the Facts?" American Journal of Managed Care, 3(2): 243-252.

Blomquist, A. (1991), "The Doctor as Double Agent: Information Asymmetry, Health Insurance and Medical Care," Journal of Health Economics, 10: 411-432.

Brisson, A.S., Frank, R.G., et al. (1998), "A Case Study in the Impact of Managed Care on Utilization and Costs of Behavioral Health Care in an HMO," NBER Working Paper $\# 6242$.

Bruce, M.L., Takeuchi, D., and Leaf, P.J. (1991), "Poverty and Psychiatric Status," Archives of General Psychiatry, 48: 470-474.

Buck, J.A. and Umland, B. (1997), "Trends: Covering Mental Health and Substance Abuse Services," Health Affairs, 16(4): 120-126.

Bureau of Labor Statistics, (1996), Tabulations from Employee Benefits in Medium and Large Private Establishments, Washington: USGPO.

Callahan, J.J., Shepard, D.S., Beinecke, R.H., Larson, M.H., and Cavanaugh, D. (1995), "Mental Health/Substance Abuse Treatment in Managed Care: The Massachusetts Medicaid Experience," Health Affairs, 14(3): 173-184.

Chang, C.F., Kiser, L.J., Bailey, J.E., Martins, M., Gibson, W.C., Schaberg, K.A., Mirvis, D.M., and Applegate, W.B. (1998), "Tennessee's Failed Managed Care Program for Mental Health and Substance Abuse Services," JAMA, 279(11): 864-869.

Christianson, J.B. et al. (1995), "Utah's Prepaid mental Health Plan: The First Year," Health Affairs, 14(3): 160-172. 
Christianson, J.B., Wholey, D., and Peterson, M.S. (1997), "Strategies for Managing Service Delivery in HMOs: An Application to Mental Health Care," Medical Care Research and Review, 54(2): 200-222.

Cooper, B. and Bauer, M. (1987), "Developments in Mental Health Care and Services in the Federal Republic of Germany," International Journal of Mental Health, 16: 78-93.

Cornes, R. and Sandler, T. (1986), The Theory of Externalities, Public Goods and Club Goods, Cambridge University Press: Cambridge, England.

Cromwell, J., Ellis, R.P., Harrow, B., and McGuire, T.G. (1992), “A Modified TEFRA System for Medicare Discharges from Psychiatric Facilities,” in Frank RG and Manning (Eds.) Economics and Mental Health, Johns Hopkins University Press.

Cuffel, B., Goldman, W., and Schlesinger, H. (1998), "The Effects of Increased Mental Health Benefits and a MBHC Carve-Out on General Medical Costs," working paper.

Cutler, D. and Zeckhauser, R. (1998), "The Anatomy of Health Insurance," in Newhouse JP and Culyer AY (Eds.) Handbook of Health Economics, North Holland Press: Amsterdam.

Deb, P., Rubin, J., Wilcox-Gok, V., and Holmes, A. (1996), "Choice of Health Insurance by Families of the Mentally Ill," Health Economics, 5(1): 61-76.

Dickey, B. and Azeni, H. (1992), "Impact of Managed Care on Mental Health Services," Health Affairs, 11(3): 197-226.

Diehr, P., et al. (1984), "Ambulatory Mental Health Services Utilization in Three Provider Plans," Medical Care, 22(1): 1-13.

Duan, N., Manning, W.G., Morris, C.N., and Newhouse, J.P. (1983), "A Comparison of Alternative Models of the Demand for Medical Care," Journal of Business and Economic Statistics, 1(2): 115-126.

Elkin, I., Shea, T., Watkins, J.T., Imber, S.D., Sotsky, S.M., Collins, J.F., Glass, D.R., Pilkonis, P.A., Leber, W.R., Docherty, J.P., Fiester, S.J., and Parloff, M.B. (1989), "National Institute of Mental Health Treatment of Depression Collaborative Research Program: General Effectiveness of Treatments," Archives of General Psychiatry, 46: 971-982.

Ellis, R.P. (1986), "Rational Behavior in the Presence of Coverage Ceilings and Deductibles," Rand Journal of Economics, 17: 158-175.

Ellis, R.P. and McGuire, T.G. (1986), "Cost Sharing and Patterns of Mental Health Care Utilization," Journal of Human Resources, 21(3): 359-380.

Ellis, R.P. and McGuire, T.G. (1986), "Provider Behavior Under Prospective Reimbursement: Cost Sharing and Supply," Journal of Health Economics, xx: 129-151.

Ellis, R.P. and McGuire, T.G. (1988), "Insurance Principles and Design of Prospective Payment Systems," Journal of Health Economics, 7: 215-237.

Ellis, R.P. and McGuire, T.G. (1993), "Supply-Side and Demand-Side Cost Sharing in Health Care," Journal of Economic Perspectives, 7(4): 135-151.

Ellis, R.P. and McGuire, T.G. (1996), "Hospital Response to Prospective Payment: Moral Hazard, Selection, and Practice-Style Effects," Journal of Health Economics, 15: 257277.

Ellis, R.P., Pope, G.C., Iezzoni, L.I., Ayanian, J.Z., et al. (1986), "Diagnosis-Based Risk Adjustment for Medicare Capitation Payments," Health Care Financing Review, 17(3): 101-128. 
Ellis, R.P. (1988), "The Effect of Prior-Year Health Expenditures on Health Coverage Plan Choice," In Scheffler RM, Rossiter LF (Eds) Advances in Health Economics and Health Services Research, Greenwich, CT: JAI Press, 6: 149-170.

Ellis, R.P. (1998), "Creaming, Skimping and Dumping: Provider Competition on the Intensive and Extensive Margins," Journal of Health Economics, 17(5): 537-556.

Encinosa, W. (1988), "Risk Adjusting Health Insurance," unpublished manuscript, Agency for Health Care Policy and Research.

Ettner, S.L. and Notman, E.H. (1997), "How Well Do Ambulatory Care Groups Predict Expenditures of Mental Health and Substance Abuse Patients?" Journal of Administration and Policy in Mental Health, 24(4): 339-358.

Ettner, S.L., Frank, R.G., and Kessler, R.C. (1997), “The Impact of Psychiatric Disorder on Labor Market Outcomes," Industrial and Labor Relations Review, 51(1): 64-81.

Ettner, S.L., Frank, R.G., McGuire, T.G., Newhouse, J.P., and Notman, E.H. (1998), "Risk Adjustment of Mental Health and Substance Abuse Payments," Inquiry, 35(2): 223-239.

Fairbank, A. (1989), "Expanding Insurance Coverage to Alternate Types of Psychotherapists: Demand and Substitution Effects, "Inquiry, 26(2): 170-181.

Finch, M. et al. (1992), "The Treatment of Alcohol and drug Abuse Among Mentally Ill Medicaid Enrollees: The Utilization of Services in prepaid Plans versus Fee-for-Service Care," in Frank R and Manning W (Eds.) Economics and Mental Health, Baltimore: Johns Hopkins Press.

Frank, R.G. and Gaynor, M.S. (1995), "Incentives, Optimality and Publicly Provided Goods: The Case of Mental Health Services," Public Finance Quarterly, 23(2): 167-192.

Frank, R.G. and Gertler, P. (1991), “An Assessment of Measurement Error Bias for Estimating the Impact of Mental Distress on Earnings," Journal of Human Resources, 26(1): 154164.

Frank, R.G. and Jackson, C.A. (1989), “The Impact of Prospectively Set Hospital Budgets on Psychiatric Admissions," Social Science and Medicine, 28(8): 861-867.

Frank, R.G. and Lave, J.R. (1989), "A Comparison of Hospital Responses to Reimbursement Policies for Medicaid Psychiatric Patients," Rand Journal of Economics, 20(4): 588-600.

Frank, R.G. and Manning, W.G. (1992), Economics and Mental Health. The Johns Hopkins University Press: Baltimore.

Frank, R.G. and McGuire, T.G. (1986), "A Review of Studies of the Impact of Insurance on the Demand and Utilization of Specialty Mental Health Services," Health Services Research, 21(2): 241-266.

Frank, R.G. and McGuire, T.G. (1996), "Federal Health Financing Reform and State Mental Health Policy," in Rich and White (Eds.) Health Policy, Federalism and the American

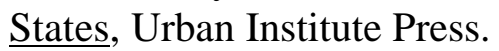

Frank, R.G. and McGuire, T.G. (1997), "Savings from a Carve-Out Program for Mental Health and Substance Abuse in Massachusetts Medicaid," Psychiatric Services, 48(9): 11471152.

Frank, R.G. and McGuire, T.G. (1998), "The Economic Functions of Carve-out in Managed Care," The American Journal of Managed Care, 4(SP): SP31-SP39. 
Frank, R.G., Lave, J.R., Taube, C.A., et al. (1987), "The Impact of Medicare's Prospective Payment System on Psychiatric Patients Treated in Scatterbeds," In Advances in Health Economics Health Services Research Scheffler R and McGuire TG (Eds.), Greenwich: JAI Press 1987, 1-21.

Frank, R.G., Glazer, J. and McGuire, T.G. (1998), "Measuring Adverse Selection in Managed Health Care," working paper.

Frank, R.G., Goldman, H.H., and McGuire, T.G. (1992), "A Model Mental Health Benefit," Health Affairs, 11(3): 98-117.

Frank, R.G., Huskamp, H.A., McGuire, T.G., and Newhouse, J.P. (1996), "Some Economics of a Mental Health Carve Out," Archives of General Psychiatry, 53: 933-957.

Frank, R.G., Koyanagi, C., and McGuire, T.G. (1997), "Political Economy of 'Parity' for Mental Health in Insurance," Health Affairs, 16(4): 108-119.

Frank, R.G., McGuire, T.G., and Newhouse, J.P. (1995), "Risk Contracts in Managed Mental Health Care," Health Affairs, 14(3): 50-64.

Frank, R.G., McGuire, T.G., Bae, J., and Rupp, A. (1997), "Solutions for Adverse Selection in Behavioral Health Care," Health Care Financing Review, 18(3): 109-122.

Frank, R.G., McGuire, T.G., Notman, E.H., and Woodward, R.M. (1996), "Developments in Medicaid Behavioral Health Care," In Mental Health U.S. 1996 Manderscheid R. and Sonnerscheid M.A. (Eds), Washington: USGPO.

Frank, R.G., McGuire, T.G., Regier, D.A., Manderscheid, R. and Woodward, A. (1994), "Paying for Mental Health and Substance Abuse Care," Health Affairs, 13(1): 337-342.

Frank, R.G., Salkever, D.S. and Sharfstein, S.S. (1991), "A Look at Rising Mental Health Insurance Costs," Health Affairs, 10(2): 116-124.

Frank, R.G. (1985), “A Model of State Expenditures on Mental Hospital Services," Public Finance Quarterly, 13(3): 319-338.

Frank, R.G. (1985), "Pricing and Location of Physician Services in Mental Health," Economic Inquiry, 23: 115-133.

Frank, R.G. (1989), "Regulatory Policy and Information Deficiencies in the Market for Mental Health Services," Journal of Health Politics, Policy and Law, 14(3): 477-503.

Freiman, M.P., Ellis, R.P., and McGuire, T.G. (1989), "Provider Response to Medicare's PPS: Reductions in Length of Stay for Psychiatric Patients Treated in Scatter Beds," Inquiry, 26(2): 192-201.

Freiman, M.P., Mitchell, J.B., and Rosenbach, M.L. (1987), "Modifications of the Prospective Payment System and Payments for Medicare Psychiatric Admissions," In McGuire, TG, Scheffler, RM (Eds) The Economics of Mental Health Services: Advances in Health Economics and Health Services Research, Greenwich, CT and London, UK: JAI Press, 8: 23-47.

Frisman, L.K., McGuire, T.G., and Rosenbach, M.L. (1985), "Costs of Mandates for Outpatient Mental Health Care in Private Health Insurance," Archives of General Psychiatry, 42: 558-561.

Glazer, J. and McGuire, T.G. (1998). "Optimal Risk Adjustment in Markets with Adverse Selection: An Application to Managed Health Care," working paper.

Goldman, H.H. and Skinner, A. (1989), "Specialty Mental Health Services: Research on Specialization and Differentiation," in Taube C, Mechanic D, and Hohmann A (Eds.) The Future of Mental Health Services Research, Washington: USGPO. 
Goldman, W., McCulloch, J., and Sturm, R. (1997), "Costs and Utilization of Mental Health Services Before and After Managed Care," Working Paper No. 108, Research Center on Managed Care for Psychiatric Disorders, UCLA.

Goulam, G. and Smith, J. (1990), Evaluation of the CPA-Norfolk Demonstration: Final Report. Department of Defense Contract MDA 907-87-C-0003, Cambridge, MA: Abt Associates.

Grob, G.N. (1973), Mental Institutions in America: Social Policy to 1875, New York: Free Press.

Grob, G.N. (1994), "Government and Mental Health Policy: A Structural Analysis," The Milbank Memorial Fund Quarterly, 72(3): 471-499.

Grob, G.N. (1991), From Asylum to Community: Mental Health Policy in Modern America, Princeton University Press: Princeton, NJ.

Gronfein, W. (1985), "Incentives and Intentions in Mental Health Policy: A Comparison of the Medicaid and Community Mental Health Programs," Journal of Health and Social Behavior, 26: 192-206.

Haas, P.J. (1989), "A Comparative Analysis of State Mental Health Policy," Journal of Management Science \& Policy Analysis, 6(4): 8-27.

Harrow, B. and Ellis, R.P. (1992), "Mental Health Provider Response to the Reimbursement System," in Frank R and manning W (Eds.) Economics and Mental Health, Baltimore: Johns Hopkins Press, 19-39.

Hodgkin, D., Horgan, C.M., and Garnick, D.W. (1997), "Make or Buy: HMOs' Contracting Arrangements for Mental Health Care," Administration and Policy in Mental Health, 24(4): 359-376.

Hodgkin, D. (1992), “The Impact of Private Utilization Management of Psychiatric Care: A Review of the Literature," Journal of Mental Health Administration, 19(2): 143-157.

Hollingsworth, E.J. (1992), "Falling Through the Cracks: Care of the Chronically Mentally Ill in the United States, Germany, and the United Kingdom," Journal of Health Politics, Policy and Law, 17(4): 899-928.

Horgan, C.M. and Jencks, S. (1987), "Research on Psychiatric Classification and Payment Systems," Medical Care, 25(9): 522-536.

Horgan, C.M. (1986), "The Demand for Ambulatory Mental Health Services from Specialty Providers," Health Services Research, 21(2): 291-320.

Hoult, J. et al. (1983), "A Controlled Study of Psychiatric Hospital versus Community Treatment: The Results of a Randomized Trial," Australia and New Zealand Journal of Psychiatry, 37: 26-31.

Huskamp, H.A. (1997), "The Impact of a Managed Behavioral Health Care Carve-Out and Benefit Expansion on Outpatient Spending for Mental Health and Substance Abuse Services," doctoral dissertation, Harvard University.

Hustead, E. and Sharfstein, S.S. (1978), "Utilization and Costs of Mental Illness Coverage in FEHBP, 1973," American Journal of Psychiatry, 135(3): 315-319.

Institute of Medicine. (1993), Employment and Health Benefits, Washington: NAS Press.

Institute of Medicine. (1997). Managing Managed Care, Washington: NAS Press.

J.P. Weiner, (1996), Personal Communication.

Jacobsen, K., McGuire, T.G. and Notman, E.H. (1996), “Organizational Structure and State Mental Health Expenditures," Administration and Policy in Mental Health, 23(6): 475492.

Jencks, C. (1994), The Homeless, Cambridge: Harvard University Press. 
Jencks, S.F. (1985). "Recognition of Mental Distress and Diagnosis of Mental Disorder in Primary Care," JAMA, 253(13): 1903-1907.

Jencks, S.F and Goldman, H.H. (1987), "Implications of Research on Prospective Payment," Medical Care, 25(9): S42-S51.

Kaplan, R.M. (1995). "Utility Assessment for Estimating Quality Adjusted Life Years," in Sloan F (Ed.) Valuing Health Care, Cambridge University Press: Cambridge UK.

Kapp, M. (1990), "Economic Barriers to Innovation in Mental Health Care: Community Care in the United Kingdom," In Mental Health Care Delivery, Marks IM and Scott R (Eds.) Cambridge: Cambridge University Press.

Keeler, E.B. et al. (1986), The Demand for Episodes of Mental Health Services, Santa Monica: Rand Report R-3432-NIMH.

Keeler, E.B., Manning, W.G., and Wells, K.B. (1988), “The Demand for Episodes of Mental Health Services," Journal of Health Economics, 7(2): 369-392.

Keeler, E.B., Newhouse, J.P., and Phelps, C.E. (1997), "Deductibles and Demand: A Theory of the Consumer Facing a Variable Price Schedule Under Uncertainty," Econometrica, 45(3): 641-655.

Keeler, E.B., Carter, G.M. and Newhouse, J.P. (1998), "A Model of the Impact of

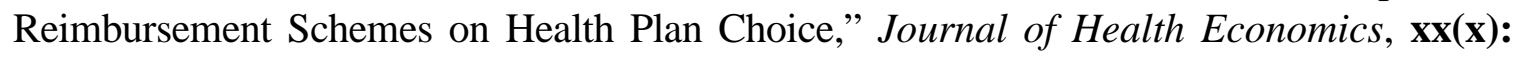
pp-pp.

Kelleher, K., Chaffin, M., Hollenberg, J., and Fischer, E. (1994), "Alcohol and Drug Disorders Among Physically Abusive and Neglectful Parents in a Community-Based Sample," American Journal of Public Health, 84: 1586-1590.

Kenkel, D.S. and Ribar, D.C. (1994), “Alcohol Consumption and Young Adults' Socioeconomic Status," Brookings Papers in Microeconomics.

Kessler, R.C., McGonagle, K., Zhao, S., Nelson, C., Hughes, M., Eshleman, S., Wittehen, H., and Kendler, K. (1994), "Lifetime and 12-Month Prevalence of DSM-III-R Psychiatric Disorders in the United States," Archives of General Psychiatry, 51(1): 8-19.

Kessler, R.C., Frank, R.G., Edlund, M., et al. (1997), "Differences in the Use of Psychiatric Outpatient Services Between the United States and Ontario," New England Journal of Medicine, 336(8): 551-557.

Knapp, M. (1997), "Cost Effectiveness Accountability and Their Relationship to Alternative Fiscal Mechanisms: Results from Great Britain and the United States," Proceedings Mental Health and Fiscal Reform, The Clarke Institute: Toronto, Canada.

Knesper, D.J. (1989), "Substitution in Production as the Basis for Research and Policy Relevant to Mental Health Specialists," in Taube C, Mechanic D, and Hohmann A (Eds.) The Future of Mental Health Services Research, Washington:USGPO.

Kouzis, A.C. and Eaton, W.W. (1994), "Emotional Disability Days: Prevalence and Predictors," American Journal of Public Health, 84(8): 1304-1307.

Kronick, R. et al. (1996), "Diagnostic Risk Adjustment for Medicaid: The Disability Payment System," Health Care Financing Review, 17(3): 7-34.

Kupfer, D.J. et al. (1992), "Five Year Outcomes for Maintenance Therapies in Recurrent Depression," Archives of General Psychiatry, 49: 769-773.

Lambrinos, J. and Rubin, J. (1981), "The Determinants of Average Daily Census in Public Mental Hospitals: A Simultaneous Model," Medical Care, 19(9): 895-906. 
Lave, J.R. and Frank, R.G. (1988), "Factor Affecting Medicaid Patients' Length of Stay in Psychiatric Units: The Effect of Provider Incentives," Health Care Financing Review, 10(2): 57-66

Lave, J.R. and Frank, R.G. (1990), “The Effect of the Structure of Hospital Payment on Length of Stay," Health Services Research, 25(2): 327-348.

Lave, J.R., Frank, R.G., Taube, C.A., et al. (1988), "PPS and Psychiatry: The First Year," Inquiry, 25(3): 354-363.

Link, B.G., Andrews, H., and Cullen, F.T. (1992), "The Violent and Illegal Behavior of mental Patients Reconsidered," American Sociological Review, 57: 275-292.

Link, et al. (1986), "Contact with the Mentally ill and Perceptions of How Dangerous they Are," Journal of Health and Social Behavior, 27(4): 289-302.

Lowry, R., Holtzman, D., Truman, B.I., Kann, L., Collins, J.L. and Kolbe, L.J. (1994), "Substance Use and HIV-Related Sexual Behaviors Among US High School Students: Are They Related?" American Journal of Public Health, 84: 1116-1120.

Lurie, N., Moscovice I.S., Finch, M., Christianson, J.B., and Popkin, M.K. (1992), "Does Capitation Affect the Health of the Chronically Mentally Ill? Results from a Randomized Trial," Journal of the American Medical Association, 267(24): 3300-3304.

Ma, C.A. (1995), "Health Care Payment Systems: Cost and Quality Incentives," Journal of Economics \& Management Strategy, 3(1): 93-112.

Ma, C.A. and McGuire, T.G. (1997), "Optimal Health Insurance and Provider Payment," American Economic Review, 87(4): 685-704.

Ma, C.A. and McGuire, T.G. (1998), "Network Effects in Managed Health Care," working paper, Boston University.

Mangen, S.P. and Rao, B. (1985), "United Kingdom: Socialised System-Better Services?” in Mangen SP (Ed.) Mental Health Care in the European Community, London: Croom Helm Books.

Mangen, S.P. (1985), “Germany: The Psychiatric Enquete and Its Aftermath,” in Mangen SP (Ed.) Mental Health Care in the European Community, London: Croom Helm Books.

Manning, W.G. et al. (1981), "The Two-Part Model of the Demand for Medical Care: Preliminary Results from the Health Insurance Study," in Van der Gaag J and Perlman M (Eds.) Health, Economics and Health Economics, Amsterdam: North Holland.

Manning, W.G., Wells, K.B., Buchanan, J.L., Keeler, E.B., Valdez, E.B., and Newhouse, J.P. (1989), "Effects of Mental Health Insurance: Evidence from the Health Insurance Experiment," RAND R-3015-NIMH/HCFA.

Manning, W.G. and Frank, R.G. (1992), "Econometric Issues in the Demand for mental Health Care under Insurance," in Frank R. and Manning W. (Eds.) Economics and Mental Health, Baltimore: Johns Hopkins Press.

Manning, W.G. and Marquis, S. (1992), "Effect of Mental Health Insurance: Evidence from the HIE," working paper, University of Michigan.

Marmor, T.R. and Gill, K.C. (1989), "The Political and Economic Context of Mental Health Care in the United States," Journal of Health Politics, Policy, and Law, 14(3): 459-475.

Matus, M. et al. (1986), "Mental Illness and the Media: II, Context Analysis of Press Coverage of Mental Health Topics," Canadian Journal of Psychiatry, 31(5): 431-433.

McKusick, D., Mark, T., King, E., et al. (1998), "Spending for Mental Health and Substance Abuse Treatment 1996," Health Affairs, 17(5): 147-157. 
McGuire, T.G. (1989), "Financing and Reimbursement of Mental Health Services," Taube and Mechanic (Eds.) The Future of Mental Health Services Research, National Institute of Mental Health.

McGuire, T.G. (1994), "Predicting the Costs of Mental Health Benefits," Milbank Memorial Fund Quarterly: Health And Society, 72(1): 3-23.

McGuire, T.G. (1996) "Commentary," [on Rizzo and Blumenthal. "Is the Target Income Hypothesis an Economic Heresy?'] Medical Care Research and Review, 53(3): 267-273.

McGuire, T.G. and Ellis, R.P. (1990), “Optimal Payment Systems for Health Services," Journal of Health Economics, 9: 375-396.

McGuire, T.G. and Montgomery, J. (1982). "Mandated Mental Health Benefits in Private Health Insurance Policies," Journal of Health Politics, Policy and Law, 7(2): 380-406.

McGuire, T.G. and Riordan, M.H. (1995), "Incomplete Information and Optimal Market Structure: Public Purchases from Private Providers," Journal of Public Economics, 56:125-141.

McGuire, T.G. (1981), Financing Psychotherapy: Costs Effects and Public Policy, Cambridge, MA.

McGuire, T.G. (1998), "Physician Agency," In Newhouse, J.P. and Culyer AY (Eds.) Handbook of Health Economics, North Holland Press: Amsterdam.

Mechanic, D., Schlesinger, M., and McAlpine, D. (1995), "Management of Mental Health and Substance Abuse Services: State of the Art and Early Results," Milbank Memorial Fund Quarterly, 73: 19-55.

Mechanic, D. (1997), "Muddling Through Elegantly: Finding the Proper Balance in Rationing," Health Affairs, 16(5): 83-92.

Mechanic, D. (1998), "The Functions and Limitations of Trust in Provision of Medical Care," Journal of Health Politics, Policy and Law, 23(4): 661-686.

MedPac. (1998), Report to Congress: Medicare Payment Policy, Washington: USGPO.

Mental Health, United States, 1996. Washington, USGPO, 1996.

Merrick, E.L. (1997) "Impact of a Behavioral Health Carve Out on Treatment of Major Depression," doctoral dissertation, Barndeis University.

Michael, R.J. (1980), "Bureaucrats, Legislators and the Decline of the State Mental Hospital," Journal of Economics and Business, 32(3): 198-205.

Miller, R.H. and Luft, H.S. (1997), "Does Managed Care Lead to Better or Worse Quality of Care?" Health Affairs, 16(5): 7-25.

Moon, M. (1996), "The Special Health Care Needs of the Elderly," in Altman S and Reinhardt U (Eds.) Strategic Choices for a Changing Health Care System, Chicago: Health Administration Press.

Morlock, L.L. (1989), "Recognition and Treatment of mental Health Problems in the General Sector," in Taube C, Mechanic D and Hohmann H (Eds.) The Future of Mental Health Services Research, Washington: USGPO.

Mullahy, J. and Sindelar, J.L. (1993), "Alcoholism, Work and Income," Journal of Labor Economics, 11(3): 494-520.

Mullahy, J. and Sindelar, J. (1990), "Gender Differences in the Effects of Mental Health on Labor Force Participation," in Sirageldin I, Sarkin A, and Frank, R.G. (Eds.) Research in Human Capital and Development. Greenwich, CT: JAI Press, pp.125-145. 
Mulvey, E.P. (1994), “Assessing the Evidence of a Link Between Mental Illness and Violence," Hospital and Community Psychiatry, 45(7): 663-668.

National Advisory Mental Health Council (1997)

Newhouse, J.P. and Phelps, C.E. (1976), "New Estimates of Price and Income Elasticities for Medical Care Services," in Rosett R (Ed.) The Impact of Health Insurance on the Health Services Sector, New York: National Bureau of Economic Research.

Newhouse, J.P. and the Insurance Experiment Group (R.W. Archibald, H.L. Bailit, R.H. Brook, M. Brown, A.R. Davies, N. Duan, G.A. Goldberg, E.B. Keeler, A. Leibowitz, K.N. Lohr, W.G. Manning, K.H. Marquis, M.S. Marquis, C.N. Morris, C.E. Phelps, W.H. Rogers, C.A. Sherbourne, R.B. Valdez, J.E. Ware, K.B. Wells). (1993), Free for All? Lessons from the RAND Health Insurance Experiment, Cambridge: Harvard University Press.

Newhouse, J.P., Beeuwkes Buntin, M., and Chapman, J.D. (1997), "Risk Adjustment and Medicare: Taking a Closer Look," Health Affairs, 16: 26-43.

Newhouse, J.P., Manning, W.G., Keeler, E.B. and Sloss, E. (1989), “Adjusting Capitation Rates Using Objective Health Measures and Prior Utilization," Health Care Financing Review, 10(3): 41-54.

Newhouse, J.P., Phelps, C.E., and Marquis, M.S. (1980), "On Having Your Cake and Eating It Too: Econometric Problems in Estimating the Demand for Health Services," Journal of Econometrics, 13(3): 365-390.

Newhouse, J.P. (1994), "Patients at Risk: Health Reform and Risk Adjustment," Health Affairs, 13(1): 132-146.

Newhouse, J.P. (1996), "Reimbursing Health Plans and Health Providers: Selection versus Efficiency in Production," Journal of Economic Literature, 34(3): 1236-1263.

Nunnally, J. (1961), Popular Conceptions of Mental Health: Their Development and Change, New York: Holt, Rinehart and Winston.

O'Flaherty, B. (1996), Making Room: The Economics of Homelessness, Cambridge: Harvard University Press.

Office of Mental Health, State of New York. (1996), Managed Behavioral Health Care for Medicaid, unpublished memo.

Oss, M. (1995). Managed Behavioral Health Market Share in the United States, Gettysburg, PA: Open Minds.

Padgett, D. et al. (1993), "The Effect of Insurance Benefit Changes and Use of Child and Adolescent Outpatient mental Health Services," Medical Care, 31(2): 96-110.

Pauly, M.V. (1968), The Economics of Moral Hazard: Comment," American Economic Review, 58: 531-537.

Pauly, M.V. (1985), "What is Adverse about Adverse Selection?" in Advances in Health Economics and Health Services Research: Biased Selection in Health Care Markets, Scheffler RM and Rossiter LF, (Eds.), Greenwich, CT: JAI Press Inc, 281-286.

Perneger, T.V., Allaz, A.F., Etter, J.F., and Rougemont, A. (1995), "Mental Health and Choice Between Managed Care and Indemnity Health Insurance," American Journal of Psychiatry, 52(7): 1020-1025.

Phelps, C.E. and Mooney, C. (1993), "Variation in medical Practice Use: Causes and Consequences," In Arnold R and White W (Eds.) Competitive Approaches to Health Care Reform, Urban Institute Press: Washington, DC.

Phelps, C.E. (1998), “Comments on Price Index Papers,” In Helms and Triplett (Eds.) 
Phelps, C.E. (forthcoming), "The Role of Information in the Supply and Demand for Health Care," In Newhouse, J.P. and Culyer AY (Eds.) Handbook of Health Economics, North Holland Press: Amsterdam.

PROPAC (1986), Report to Congress.

Ramsey, F. (1927), "A Contribution to the Theory of Taxation," Economic Journal, 37: 41-61.

Ramsey, S. and Pauly, M.V. (1997), "Structure Incentives and Adoption of Medical Technologies in HMO and Fee-for-Service Health Insurance Plans," Inquiry, 34: 228-236.

Reed, K. (1975), Coverage and Utilization of Care for Mental Health Conditions Under Health Insurance, Various Studies 1973-74, Washington: APA.

Rice, D. et al. (1990), The Cost of Alcohol and Drug Abuse and Mental Illness, Washington: USGPO.

Rice, T. (1998), The Economics of Health Reconsidered, Health Administration Press: Chicago.

Rochefort, D.A. (1993), From Poor Houses to Homelessness, Westport: Auburn House.

Rothschild, M. and Stiglitz, J. (1976), "Equilibrium in Competitive Insurance Markets: An Essay in the Economics of Imperfect Information," Quarterly Journal of Economics, 90: 629649.

Rubin, J. (1978), Economics, Mental Health, and the Law, D.C. Heath and Company: Lexington, MA.

Rubin, J. (1980), "Judicial Standards and the Financing of Mental Health Services," Inquiry, 17(2): 165-171.

Rupp, A., Steinwachs, D.M. and Salkever, D.S. (1984), "The Effect of Hospital Payment Methods on Patterns and Cost of Mental Health Care," Hospital and Community Psychiatry, 35(5): 450-458.

Scheffeler, R.M. and Watt, C.A. (1986), "Inpatient Mental Health Use among the Heavily Insured," Journal of Human Resources, 21(3): 338-358.

Scheffeler, R.M., Grogan, C., Cuffel, B., and Penner, S. (1994), “A Specialized Mental Health Plan for Persons with Severe Mental Illness under Managed Competition," Hospital and Community Psychiatry, 44: 937-942.

Secretary of the Department of Health and Human Services. (1993), Alcohol and Health, USGPA: Washington, DC, Chapter 9.

Segal, S., Silverman, C., and Baumohl, J. (1989), "Seeking Person-Environment Fit in Community Care Placement," Journal of Social Issues, 45(3): 49-64.

Shapiro, S., German, P., Skinner, A., et al. (1987), "An Experiment to Change Detection and Management of Mental Health Morbidity in Primary Care," Medical Care, 25(4): 327339.

Shen, Y. and Ellis, R.P. (1998), "Cost Minimizing Risk Adjustment," working paper, Boston University.

Steadman, H.J., Mulvey, E.P., Monohan, J., Robbins, P.C., Appelbaum, P.S., Grisso, T., Roth, L.H., and Silver, E. (1998), "Violence by People Discharged from Acute Psychiatric Inpatient Facilities and by others in the Same Neighborhoods," Archives of General Psychiatry, 55: 1-9.

Stein, L.I. and Test, M.A. (1980), "Alternative to Mental Hospital Treatment," Archives of General Psychiatry, 37: 392-397.

Sturm, R. (1997), "How Expensive is Unlimited Mental Health Care Coverage under Managed Care?" JAMA, 278: 1533-1537. 
Sturm, R. et al. (1994), "Provider Choice and Continuity for the Treatment of Depression," Rand paper DRU-692-AHCPR.

Swendsen, J.D., Merikangas, K.R., Canino, G.J., Kessler, R.C., Rubio-Stipec, M., and Angst, J. (1998), "The Comorbidity of Alcoholism with Anxiety and Depressive Disorders in Four Geographic Communities," Comprehensive Psychiatry, 39: 176-184.

Taube, C.A., Kessler, L.G., and Burns, B.J. (1986), "Estimating the Probability and Level of Ambulatory Mental Health Services Use," Health Services Research, 21(2): 321-340.

Torrey, F.E. (1994), "Violent Behavior by Individuals with Serious Mental Illness," Hospital and Community Psychiatry, 45(7): 653-662.

Triplett, J.E. (1998), "What's Different About Health? Human Repair and Care Repair in National Accounts," Health Affairs, (in press).

Umland, B. (1995), "Behavioral Healthcare Benefit Strategies of Self-Insured Employers," Behavioral Healthcare Tomorrow, vol: 65-70.

Von Korff, M. and Kramer, M. (1978), "Mental and Nervous Disorders Utilization and Cost Survey," NIMH and OPM, Washington.

Wallack, S.S. and Levine, H.J. (1996), "Managed Care for People with Disabilities: Caring for those with the Greatest Need - Overview," in Altman S and Reinhardt U (Eds.) Strategic Choices for a Changing Health Care System, Chicago: Health Administration Press.

Watts, C.A., Scheffler, R.M., and Jewell, N.P. (1986), "Demand for Outpatient Mental Health Services in a Heavily Insured Population: The Case of the Blue Cross and Blue Shield Association's Federal Employees Health Benefits Program," Health Services Research, 21(2): 267-290.

Weiner, J.P., Dobson, A., Maxwell, S.L., Coleman, K., Starfield, B.H., and Anderson, G.F. (1996), "Risk-Adjusted Capitation Rates Using Ambulatory and Inpatient Diagnoses," Health Care Financing Review, 17(3): 77-99.

Weinstein, M.C. and Zeckhauser, R.J. (1972), “Critical Ratios and Efficient Allocation,” Journal of Public Economics, 2(2): 147-157.

Weinstein, M.C. (1995), "From Cost-Effectiveness Ratios to Resource Allocation: Where to Draw the Line," In Sloan F (Ed.) Valuing Health Care, Cambridge University Press: Cambridge UK.

Weisbrod, B.A. (1983), "A Guide to Benefit-Cost Analysis as Seen through a Controlled Experiment in Treating the Mentally Ill," Journal of Health Politics, Policy and Law, 7(4): 88-845.

Wells, K.B. et al. (1996), Caring for Depression, Cambridge: Harvard University Press.

World Health Organization. (1994), Global Comparative Assessments in the Health Sector: Disease Burden Expenditures and Intervention Packages, Geneva: WHO.

Yellowlees, H. (1990), "Administrative Barriers to Implementation and Diffusion of Innovative Approaches to Mental Health Care in the United Kingdom," In Marks IM and Scott RA (Eds.) Mental Health Care Delivery: Innovations, Impediments and Implementation. Cambridge: Cambridge University Press.

Zeckhauser, R. (1970), "Medical Insurance: A Case Study of the Trade-Off Between RiskSpreading and Appropriate Incentives," Journal of Economic Theory, 2: 10-26. 